\title{
The Strength of Low-Cloud Feedbacks and Tropical Climate: A CESM Sensitivity Study
}

\author{
EHSAN ERFANi AND NATALIE J. BuRLS \\ Center for Ocean-Land-Atmosphere Studies, George Mason University, Fairfax, Virginia
}

(Manuscript received 23 August 2018, in final form 8 February 2019)

\begin{abstract}
Variability in the strength of low-cloud feedbacks across climate models is the primary contributor to the spread in their estimates of equilibrium climate sensitivity (ECS). This raises the question: What are the regional implications for key features of tropical climate of globally weak versus strong low-cloud feedbacks in response to greenhouse gas-induced warming? To address this question and formalize our understanding of cloud controls on tropical climate, we perform a suite of idealized fully coupled and slab-ocean climate simulations across which we systematically scale the strength of the low-cloud-cover feedback under abrupt $2 \times \mathrm{CO}_{2}$ forcing within a single model, thereby isolating the impact of low-cloud feedback strength. The feedback strength is varied by modifying the stratus cloud fraction so that it is a function of not only local conditions but also global temperature in a series of abrupt $2 \times \mathrm{CO}_{2}$ sensitivity experiments. The unperturbed decrease in low cloud cover (LCC) under $2 \times \mathrm{CO}_{2}$ is greatest in the mid- and high-latitude oceans, and the subtropical eastern Pacific and Atlantic, a pattern that is magnified as the feedback strength is scaled. Consequently, sea surface temperature (SST) increases more in these regions as well as the Pacific cold tongue. As the strength of the low-cloud feedback increases this results in not only increased ECS, but also an enhanced reduction of the large-scale zonal and meridional SST gradients (structural climate sensitivity), with implications for the atmospheric Hadley and Walker circulations, as well as the hydrological cycle. The relevance of our results to simulating past warm climate is also discussed.
\end{abstract}

\section{Introduction}

\section{a. Cloud feedbacks}

Global warming in response to rising atmospheric $\mathrm{CO}_{2}$ levels is often quantified using equilibrium climate sensitivity (ECS), which is defined as the increase in the global mean surface temperature, after the system has equilibrated, due to an atmospheric $\mathrm{CO}_{2}$ doubling. ECS is primarily affected by climate feedback processes that strengthen or weaken the system response to $\mathrm{CO}_{2}$ induced warming [for an overview of various climate feedbacks, see Flato et al. (2013)].

There is considerable uncertainty in determining the sign and magnitude of cloud feedbacks. Based on both climate models and observations, the Intergovernmental Panel on Climate Change Fifth Assessment Report (IPCC AR5) estimates that the net cloud feedback is likely positive, $+0.6 \mathrm{~W} \mathrm{~m}^{-2}{ }^{\circ} \mathrm{C}^{-1}$ with an uncertainty range of -0.2 to $+2.0 \mathrm{~W} \mathrm{~m}^{-2}{ }^{\circ} \mathrm{C}^{-1}$ (IPCC 2013). This uncertainty is largely due to the spread in low-level

Corresponding author: Ehsan Erfani, eerfani@gmu.edu cloud responses seen across the global climate models (GCMs) participating in phases 3 and 5 of the Coupled Model Intercomparison Projects (CMIP3 and CMIP5) (Bony and Dufresne 2005; Webb et al. 2006; Sherwood et al.2014) and is the main source of the GCMs spread in ECS estimates $\left(2^{\circ}-4.6^{\circ} \mathrm{C}\right)$ (Bony et al. 2006; Vial et al. 2013; Caldwell et al. 2016).

The three fundamental components contributing to the net cloud feedback are cloud amount, cloud altitude, and cloud optical depth feedbacks [for a review on cloud feedbacks, see Zelinka et al. (2017)]. In this study, we specifically investigate the low-level cloud amount feedback. Stratus clouds in the tropical and subtropical regions generally display a positive cloud amount feedback (Zelinka et al. 2012; Geoffroy et al. 2017) with their coverage decreasing as surface temperatures rise; however, the spatial structure is not homogeneous.

Uncertainty in low-cloud feedbacks is largely due to the parameterization of subgrid processes, such as sensitivity to shallow convective mixing parameters (Tomassini et al. 2015; Sherwood et al. 2014; Brient et al. 2016; Vial et al. 2017). To address this, Bretherton (2015) used highresolution large eddy simulations and cloud-resolving 
model to simulate tropical and subtropical stratus and cumulus clouds. The results shed light on our understanding of low-cloud feedbacks by investigating the central mechanisms controlling the response of marine boundary layer (MBL) stratocumulus to warming, with the balance of positive and negative feedback processes leading to reduced cloudiness and a net positive shortwave cloud feedback, in agreement with GCMs.

Another complicating factor in evaluating the strength of low-cloud feedbacks is that cloud feedbacks are not time-invariant. Using CMIP5 simulations with instantaneously quadrupled $\mathrm{CO}_{2}$ levels, Andrews et al. (2015) show that time-varying cloud feedbacks lead to nonlinear ECS as delayed ocean heating and the adjustment of surface warming patterns allow new cloud feedbacks to come into play. The majority of this temporal evolution in cloud feedbacks happens in the Southern Ocean (Armour et al. 2013) and eastern tropical Pacific (Andrews et al. 2015; Ceppi and Gregory 2017; Andrews and Webb 2018). The mechanisms behind this nonlinearity are not well understood due to the complicated atmosphere-ocean processes, especially in the equatorial Pacific (Collins et al. 2010). Another complicating factor is teasing out cloud feedback signals associated with natural variability from those due to greenhouse gas-induced warming (Zhou et al. 2016; Mauritsen 2016; Andrews and Webb 2018).

In this study we aim to systematically evaluate the implications of globally weak versus strong low-cloud feedbacks for key climate features, specifically the meridional temperature gradient, the hydrological cycle and the mean state for the tropical Pacific. The motivation behind this is twofold. This analysis aims to provide insight into the link between model-dependent low-cloud feedback strength and the response of these key climate features across climate change projections. Second, this sensitivity study assesses the extent to which strongly positive low-cloud feedbacks could aid in simulating past warm climates.

A persistent challenge in modeling the past warm climates of the Pliocene, Miocene, and Eocene is reproducing the polar amplified warming, the muted tropical warming, and the much weaker equator-to-pole temperature gradients that characterized them (Huber and Caballero 2011; Lunt et al. 2013; Goldner et al. 2014; Fedorov et al. 2013; Dowsett et al. 2013; Salzmann et al. 2013; Evans et al. 2018). This has implications for capturing associated east-west SST gradient changes in the equatorial Pacific (e.g., Burls and Fedorov 2014a; Fedorov et al. 2015). This data-model mismatch has become known as the equable climate problem (Sloan and Barron 1990; Huber and Caballero 2011; Huber 2013). Required changes in cloud radiative forcing, which GCMs fail to produce, appear to be at the heart of this problem. This could be rooted in one of two main mechanisms: 1) the inability of parameterized cloud physics to resolve key cloud feedback responses under warming or 2) missing aerosol indirect effects. Missing cloud radiative forcing mechanisms that have been proposed include high-latitude cloud feedbacks due to longwave trapping by convective clouds (Abbot and Tziperman 2008a,b), optically thick low clouds (Cronin and Tziperman 2015; Cronin et al. 2017) and polar stratospheric clouds (Sloan et al. 1992; Peters and Sloan 2000; Kirk-Davidoff et al. 2002), altered midlatitude and tropical cloud radiative forcing (Sagoo et al. 2013; Burls and Fedorov 2014b), and altered natural aerosol concentrations (Kump and Pollard 2008; Kiehl and Shields 2013; Unger and Yue 2014; Upchurch et al. 2015). Here we explore the extent to which amplified low-level cloud feedbacks might address this issue, paying particular attention to reducing tropical meridional and zonal temperature gradients (Fedorov et al. 2015), and the hydrological response (Burls and Fedorov 2017).

\section{b. Mechanisms controlling large-scale surface temperature gradients}

The meridional (equator to midlatitudes) and equatorial zonal (east-west) surface temperature gradients control the Walker and Hadley circulations, respectively, and are critical characteristics of tropical climate. In this subsection, we briefly summarize important (equilibriumclimate) mechanisms controlling these surface temperature gradients in both slab-ocean models (SOMs) and fully coupled models (FCMs), and in section $3 \mathrm{e}$ we explain how these mechanisms relate to our results.

The weakening of the zonal SST gradient as a function of warming, without ocean dynamics, is investigated by Merlis and Schneider (2011, hereafter MS11) who use a cloud-free, idealized atmospheric GCM coupled to a SOM. The lack of clouds in their model means that the net shortwave (SW) gradient is zero and therefore the surface energy balance is primarily between the zonal gradient in the surface latent heat flux (LE) and the gradient in the $Q$ flux (QF: ocean energy flux divergence that accounts for the effect of the ocean circulation on SST): $\Delta(\mathrm{QF}) \sim \Delta \mathrm{LE}$, where $\Delta$ is the east-west gradient [MS11, their Eq. (4) and Fig. 3]. MS11 present a scaling for the zonal SST gradient that describes their GCM results. The LE is approximated as a linear function of the saturation specific humidity $\left(q_{s}\right)$ using the bulk aerodynamic formula [MS11, their Eq. (5)]. In the tropics, the zonal LE gradient scales with the zonal $q_{s}$ gradient [MS11, their Eq. (6)]: $\Delta \mathrm{LE} \sim \Delta q_{s}\left(T_{s}\right)$, where $q_{s}$ is strongly dependent of surface temperature $\left(T_{s}\right)$. To derive a temperature gradient scaling, $q_{s}$ is linearized 
[MS11, their Eq. (7)]: $\Delta q_{s}\left(T_{s}\right) \sim\left(\partial q_{s} / \partial T\right) \Delta T_{s}$. Then, by rearranging this equation, the zonal surface temperature gradient is obtained as a function of $\Delta q_{s}$ and an inverse function of the rate of change of $q_{s}$ with temperature [MS11, their Eq. (8) and Fig. 2]: $\Delta T_{s} \sim \Delta q_{s}\left(\partial q_{s} / \partial T\right)^{-1}$, which can also be stated as $\Delta T_{s} \sim \Delta \operatorname{LE}\left(\partial q_{s} / \partial T\right)^{-1}$. Since $\mathrm{QF}$ is invariant across their simulations, $\Delta \mathrm{LE}$ must remain invariant, and therefore the zonal $T_{s}$ gradient decreases with warming to the extent that $q_{s}$ increases with temperature (based on the Clausius-Clapeyron relationship). The physical interpretation of this equation can be understood by the following counterexample (as explained by MS11): if the zonal SST gradient was unchanged with warming, the zonal LE gradient would increase continuously with warming, and such large LE gradient would not balance the prescribed QF. Knutson and Manabe (1995) first pointed out this sensitivity of evaporative cooling to climate change and the associated weakening of surface temperature gradients with global warming in GCMs, calling it the evaporative damping mechanism. In the MS11 study the reduced zonal SST gradient is associated with a weakening of trade winds and the Walker circulation (see MS11 and references therein for a discussion of the weaker Walker scaling).

In reality, oceanic and atmospheric circulations are coupled and the QF will respond to changes in the Walker/Hadley circulation and the strength of the zonal/ meridional gradients. Liu and Huang (1997, hereafter LH97) present a theory for this coupled system based on an idealized box model that incorporates the inherent coupled response of SST gradients, atmospheric circulation, and ocean heat transport and provides a scaling for the relationship between the zonal SST gradient in the equatorial Pacific and the meridional SST gradient, as well as how the strength of both these gradients is set by the meridional gradient in the local equilibrium SST (where local equilibrium SST is defined as the SST that would occur in the absence of ocean circulation). Burls and Fedorov (2014a) and Fedorov et al. (2015) perform a series of modified cloud albedo and $\mathrm{CO}_{2} \mathrm{FCM}$ sensitivity experiments and show that the idealized box model solutions of LH97 generally agree with their simulation results.

In the idealized box model, the upper ocean (the upper $50 \mathrm{~m}$ ) is divided into three boxes (the warm pool, the cold tongue, and the extratropics), and each box is represented by a mean upper-ocean temperature. The temperature of each box is determined by an ocean QF and surface heat flux. The surface heat flux is parameterized as radiative damping toward the local equilibrium SST that would occur in the absence of ocean circulation. The Walker and Hadley circulations are coupled to the upper-ocean zonal temperature gradient $\left(\Delta T_{\mathrm{uo}, z o n a l}\right)$ and upper-ocean meridional temperature gradient $\left(\Delta T_{\mathrm{uo} \text {,meridional }}\right)$, respectively, with both these circulations determining the strength of the ocean volume transport by the ocean, wind-driven subtropical cells (STCs), which in turn controls the QF, thereby capturing the coupled nature of the system. See LH97 and Eqs. (1)-(3) in Fedorov et al. (2015) for further details.

The steady-state analytical solution of the box model is $\Delta T_{\text {uo,zonal }}=\Delta T_{\text {uo,meridional }} /(1 / Q+3 / 2-\varepsilon)$, where $\varepsilon$ is a branching parameter accounting for the poleward Ekman transport out of the cold tongue box relative to the Ekman transport out of the combined warm pool and cold tongue boxes; $Q$ is the nondimensionalized volume transport into the cold tongue box: $Q=q \tau_{r} / m_{2} ; q$ is the dimensional transport, $\tau_{r}$ is the restoring time scale of surface heat fluxes, and $m_{2}$ is the volume of the cold tongue box. This solution is not very sensitive to the range of $q$ and $\tau_{r}$ values seen across the numerical sensitivity experiments performed by Burls and Fedorov (2014a) and Fedorov et al. (2015) (see their Fig. S8) and as such a tight relationship is seen between the two gradients across these simulations following the LH97 scaling.

Utilizing the LH97 box model solutions together with a simple energy balance model, Burls and Fedorov (2014a) present a scale argument for the relationship between $\Delta T_{\mathrm{uo}, z o n a l}$ and the meridional TOA albedo gradient in the Pacific basin (see their Fig. 13a). Reducing the albedo of midlatitude clouds (weakening the meridional TOA albedo gradient) leads to an increase in the net SW radiation over the midlatitude ocean surface, which in turn increases midlatitude upper-ocean temperature and

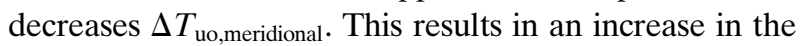
temperature of water subducted in the extratropics and transported to the equator by the meridional overturning circulation (STC), and consequently a rise in the temperature of water upwelled in the eastern equatorial Pacific, decreasing $\Delta T_{\text {uo,zonal }}$. Meanwhile, tropical albedo controls the heating of a water parcel as it travels from east to west across the equatorial Pacific. Therefore, the meridional TOA albedo gradient acts as a control on the $\Delta T_{\text {uo,zonal }}$ [for more details, see Burls and Fedorov (2014a)].

Another proposed mechanism affecting the zonal temperature gradient is the thermostat mechanism (Clement et al. 1996; Sun and Liu 1996). This mechanism asserts that the zonal SST gradient will increase under uniform global warming because warm pool SST is largely governed by the local surface heat budget while cold tongue SST is largely governed by the upwelling of cooler subsurface waters. Therefore, a uniform increase in the surface heat flux over the tropics will more effectively warm the west than the east. Off-equatorially induced changes in the temperature of subsurface waters upwelled into the cold tongue are not accounted for in 
this purely tropics-based theory and as such it has subsequently been argued that this mechanism could only operate as part of the transient adjustment to warming, while the equilibrium response is controlled by the coupled processes involving the ocean STCs and tropical extratropical interactions encapsulated by the box model (Liu 1998; Luo et al. 2017). Liu (1998) does however show that the equilibrium response of the box model to uniform heating across the tropics and extratropics can result in a strengthening of the zonal and meridional SST gradients as seen by Seager and Murtugudde (1997) [and Xie et al. (2010) for the Southern Hemisphere meridional SST gradient in climate projections]. This occurs due to latitudinal differences in the surface heat flux sensitivity to SST perturbations (Liu 1998), which effectively act to increase the meridional gradient in the local equilibrium SST. These latitudinal differences in the surface heat flux sensitivity to SST perturbations are due to the wind speed dependence of the latent heat flux, such that stronger offequatorial winds allow the uniform forcing to be balanced by a smaller SST change in the subtropics/extratropics (Seager and Murtugudde 1997). Note however that meridional differences in the strength of cloud feedbacks generally ensure that changes in radiative heating are not uniform, exerting the dominant control on the meridional gradient in the local equilibrium SST and hence the equilibrium response of zonal and meridional SST gradients, as supported by our results.

Our study aims to build on this previous work by investigating the response of these large-scale gradients, the coupled ocean-atmosphere circulation, and the hydrological response under warming when the strength of the low-cloud amount feedback is systematically varied. The experimental design of the low-cloud sensitivity experiments performed is explained in the following methodology section (section 2). The results presented in section 3 include a discussion of responses in the global means, climate sensitivity, transient adjustment, spatial distributions, meridional gradients, the hydrological cycle, and zonal gradients. Finally, the conclusions are discussed in section 4 .

\section{Methodology}

The numerical experiments in this study were performed using the Community Earth System Model (CESM), version 1.2.2, with the T31gx3v7 configuration (Shields et al. 2012). Under this setup the atmospheric component of the model [Community Atmosphere Model version 4 (CAM4)] has 26 vertical levels and a T31 spectral dynamical core that amounts to a horizontal resolution of $3.75^{\circ}$. The oceanic component [Parallel Ocean Program (POP)] has 60 vertical levels and a horizontal resolution ranging from $1^{\circ}$ at the equator to $3^{\circ}$ near the poles. To ascertain the influence of ocean dynamics this study consists of two distinct sets of experiments: the first uses the B_1850_CN CESM component set, which is FCM with the POP dynamic ocean component, and the second part uses the E_1850_CN component set in which the ocean component is a SOM with prescribed climatological $Q$ flux from the FCM control.

Our numerical experiments consist of four key steps.

Step 1: A CESM control run with preindustrial $\mathrm{CO}_{2}$ level that was run for a period of 500 years for the FCM, and 100 years for the SOM, in order to reach equilibrium. Hereafter, these experiments are called ctrl (Exp 1 for the FCM, and Exp 11 for the SOM in Table 1).

Step 2: A CESM simulation was branched from the ctrl with double $\mathrm{CO}_{2}$ levels and run for a period of 1800 years for the FCM and 100 years for the SOM. We called these experiments $2 \times \mathrm{CO}_{2}(\operatorname{Exp} 2$ for FCM, and Exp 12 for SOM in Table 1).

Step 3: As in step 2 we branch from the ctrl with double $\mathrm{CO}_{2}$ levels but we modified the stratus clouds ${ }^{1}$ using the following equation:

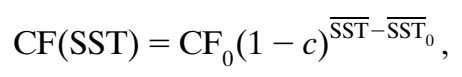

where $\mathrm{CF}_{0}$ is the default cloud fraction calculated by the model (before modification), CF is cloud fraction after modification (now a function of global mean SST), $\overline{\text { SST }}$ is globally averaged SST at each time step, $\overline{\mathrm{SST}}_{0}$ is the globally averaged SST for the last 100 years of ctrl, and $c$ is an arbitrary constant to control the strength of the modification. This approach is loosely based on the approach taken by Mauritsen and Stevens (2015) to scale the iris effect using the precipitation efficiency of convective clouds; however, here global rather than local SST changes are used. This allows us to encompass and extend the spread in low-cloud feedback strengths seen

\footnotetext{
${ }^{1}$ In the CESM cloud fraction FORTRAN code, stratus clouds and low layered clouds are calculated at each model level below $700 \mathrm{hPa}$; however, there are separate calculations for each cloud type: stratus clouds form based on an empirical relationship between marine stratus cloud fraction $\left(\mathrm{CF}_{\mathrm{st}}\right)$ and the stratification between $700 \mathrm{hPa}$ and the surface [Klein and Hartmann 1993; also see Collins et al. 2004, their Eq. (4.180)]: $\mathrm{CF}_{\mathrm{st}}=0.57\left(\theta_{700}-\theta_{s}\right)-0.5573$, where $\theta_{700}$ and $\theta_{s}$ are the potential temperatures at $700 \mathrm{hPa}$ and the surface, respectively. On the other hand, the low-layered clouds form when the relative humidity (RH) exceeds a threshold [Collins et al. 2004, their Eq. (4.184)]: $\mathrm{CF}_{\text {ll }}=\left[\left(\mathrm{RH}-\mathrm{RH}_{\min }^{\text {low }}\right) /\left(1-\mathrm{RH}_{\min }^{\text {low }}\right)\right]^{2}$, where $\mathrm{RH}_{\text {min }}^{\text {low }}$ is minimum relative humidity threshold for low-layered clouds and is equal to 0.88 for the resolution used in our study [for more details, see Collins et al. (2004, chapter 4.7)]. Hereafter, the term "stratus clouds" refers to the modification of both low layered and marine stratus clouds in the CESM cloud fraction code.
} 
TABLE 1. A description of the CESM experiments (Exp) performed in this study.

\begin{tabular}{|c|c|c|c|}
\hline Exp No. & Configuration & $\mathrm{CO}_{2}$ level & $c$ parameter \\
\hline 1 & Fully coupled & Preindustrial & No modification \\
\hline 2 & Fully coupled & $2 \times \mathrm{CO}_{2}$ & No modification \\
\hline 3 & Fully coupled & $2 \times \mathrm{CO}_{2}$ & -0.2 \\
\hline 4 & Fully coupled & $2 \times \mathrm{CO}_{2}$ & -0.15 \\
\hline 5 & Fully coupled & $2 \times \mathrm{CO}_{2}$ & -0.1 \\
\hline 6 & Fully coupled & $2 \times \mathrm{CO}_{2}$ & -0.05 \\
\hline 7 & Fully coupled & $2 \times \mathrm{CO}_{2}$ & 0.05 \\
\hline 8 & Fully coupled & $2 \times \mathrm{CO}_{2}$ & 0.1 \\
\hline 9 & Fully coupled & $2 \times \mathrm{CO}_{2}$ & 0.15 \\
\hline 10 & Fully coupled & $2 \times \mathrm{CO}_{2}$ & 0.2 \\
\hline 11 & Slab ocean & Preindustrial & No modification \\
\hline 12 & Slab ocean & $2 \times \mathrm{CO}_{2}$ & No modification \\
\hline 13 & Slab ocean & $2 \times \mathrm{CO}_{2}$ & -0.2 \\
\hline 14 & Slab ocean & $2 \times \mathrm{CO}_{2}$ & -0.15 \\
\hline 15 & Slab ocean & $2 \times \mathrm{CO}_{2}$ & -0.1 \\
\hline 16 & Slab ocean & $2 \times \mathrm{CO}_{2}$ & -0.05 \\
\hline 17 & Slab ocean & $2 \times \mathrm{CO}_{2}$ & 0.05 \\
\hline 18 & Slab ocean & $2 \times \mathrm{CO}_{2}$ & 0.1 \\
\hline 19 & Slab ocean & $2 \times \mathrm{CO}_{2}$ & 0.15 \\
\hline 20 & Slab ocean & $2 \times \mathrm{CO}_{2}$ & 0.2 \\
\hline 21 & Fully coupled & Preindustrial & -0.2 \\
\hline 22 & Fully coupled & Preindustrial & -0.15 \\
\hline 23 & Fully coupled & Preindustrial & -0.1 \\
\hline 24 & Fully coupled & Preindustrial & -0.05 \\
\hline 25 & Fully coupled & Preindustrial & 0.05 \\
\hline 26 & Fully coupled & Preindustrial & 0.1 \\
\hline 27 & Fully coupled & Preindustrial & 0.15 \\
\hline 28 & Fully coupled & Preindustrial & 0.2 \\
\hline 29 & Slab ocean & Preindustrial & -0.2 \\
\hline 30 & Slab ocean & Preindustrial & -0.15 \\
\hline 31 & Slab ocean & Preindustrial & -0.1 \\
\hline 32 & Slab ocean & Preindustrial & -0.05 \\
\hline 33 & Slab ocean & Preindustrial & 0.05 \\
\hline 34 & Slab ocean & Preindustrial & 0.1 \\
\hline 35 & Slab ocean & Preindustrial & 0.15 \\
\hline 36 & Slab ocean & Preindustrial & 0.2 \\
\hline
\end{tabular}

across CMIP5 models in one model. In our study, eight different values were assigned to $c$ parameter: -0.2 , $-0.15,-0.1,-0.05,0.05,0.1,0.15$, and 0.2. As shown in the next section, positive $c$ values correspond to a more positive low-level cloud feedback and vice versa. The larger the value of the $c$ parameter, the more extreme the reduction in low cloud cover (LCC). We found that a value of $c=0.5$ removes the stratus clouds completely, and therefore is not included this experiment in the manuscript. Exp 3-10 for the FCM, and Exp 13-20 for the SOM fall under step 3, and are run for a period of 1800 years for the FCM and 100 years for the SOM. The results presented are based on the last 100 years of the FCM and the last 80 years of the SOM simulations unless otherwise mentioned.

Step 4: To demonstrate that by varying the $c$ parameter and modifying the low-cloud feedback strength the ctrl climate remains largely unchanged we repeat each experiment in step 3, but as a branch from the ctrl with preindustrial $\mathrm{CO}_{2}$ levels for a period of 100 years for both the FCM and SOM experiments. As shown in Table 1, Exp 21-28 for the FCM and Exp 29-36 for the SOM are associated with this step. Note that the power in Eq. (1) for experiments in this step is very small and therefore we expect a negligible feedback and the conditions to remain similar to the ctrl.

To compare the simulations with observations, we calculated the observed SST climatology using data from the Hadley Centre Sea Ice and Sea Surface Temperature dataset (HadISST) from 1950 to 1999 with a horizontal resolution of $1^{\circ}$ and temporal resolution of 1 month (Rayner et al. 2003).

\section{Results}

\section{a. Global means and climate sensitivity}

We start by characterizing each simulation in terms of global means. Tables 2 and 3 show the annual, global mean SST, LCC, top of atmosphere (TOA) imbalance, and ECS for the FCM and SOM experiments, respectively. The results for SST and LCC in Tables 2 and 3 can also be seen visually in Fig. 1a. For cases with preindustrial $\mathrm{CO}_{2}$, as expected from Eq. (1), the imposed modification to the low-cloud fraction calculation leads to negligible changes in the FCM SST and LCC (Exp 2128) and small changes in the SOM SST and LCC (Exp 2936). In these experiments, since the difference between $\overline{\mathrm{SST}}$ and $\overline{\mathrm{SST}}_{0}$ remains small, CF stays close to control values $\left(\mathrm{CF}_{0}\right)$ and therefore the modification to the feedback strength is of little significance. That the SOM experiments show some weak sensitivity to the $c$ parameter under preindustrial $\mathrm{CO}_{2}$, while the FCM experiments do not, is most likely because the reduced ocean heat storage capacity in the SOM allows for a moderate low-cloud feedback in response to internal variability (Fig. 1a).

For the experiments with doubled $\mathrm{CO}_{2}$ concentrations, global mean SST values range from $18.08^{\circ}$ to $24.41^{\circ} \mathrm{C}$ for the FCM experiments and from $17.74^{\circ}$ to $25.13^{\circ} \mathrm{C}$ for the SOM experiments. As the $c$ parameter is increased from -0.2 to 0.2 global LCC decreases [based on Eq. (1)], leading to enhanced global warming in response to the same $\mathrm{CO}_{2}$ radiative forcing. $\mathrm{LCC}$ ranges from $25.69 \%$ to $39.14 \%$ for the FCM and from $24.85 \%$ to $39.17 \%$ for the SOM experiments. As expected, the most extreme positive (negative) feedback strengths lead to the warmest (coolest) global mean SST and smallest (largest) global LCC.

As summarized in Tables 2 and 3, the imposed variation in the low-cloud feedback strength result in 
TABLE 2. Annual global means of SST, LCC, TOA imbalance, and ECS for the FCM simulations.

\begin{tabular}{|c|c|c|c|c|c|c|c|}
\hline \multirow[b]{2}{*}{$c$ parameter } & \multicolumn{2}{|c|}{$\mathrm{SST}\left({ }^{\circ} \mathrm{C}\right)$} & \multicolumn{2}{|c|}{$\operatorname{LCC}(\%)$} & \multicolumn{2}{|c|}{ TOA imbalance $\left(\mathrm{W} \mathrm{m}^{-2}\right)$} & \multirow[b]{2}{*}{ ECS $\left({ }^{\circ} \mathrm{C}\right)$} \\
\hline & Preindustrial $\mathrm{CO}_{2}$ & $2 \times \mathrm{CO}_{2}$ & Preindustrial $\mathrm{CO}_{2}$ & $2 \times \mathrm{CO}_{2}$ & Preindustrial $\mathrm{CO}_{2}$ & $2 \times \mathrm{CO}_{2}$ & \\
\hline No modification & 16.59 & 18.78 & 37.65 & 37.33 & 0.0465 & 0.0350 & 3.08 \\
\hline-0.2 & 16.53 & 18.08 & 37.62 & 39.14 & 0.0699 & -0.0054 & 2.18 \\
\hline-0.15 & 16.51 & 18.20 & 37.60 & 38.82 & 0.0923 & 0.0352 & 2.35 \\
\hline-0.1 & 16.53 & 18.32 & 37.63 & 38.46 & 0.0596 & 0.0349 & 2.50 \\
\hline-0.05 & 16.53 & 18.52 & 37.64 & 37.94 & 0.0751 & 0.0350 & 2.76 \\
\hline 0.05 & 16.60 & 19.31 & 37.65 & 36.20 & 0.0968 & 0.0722 & 3.77 \\
\hline 0.1 & 16.61 & 20.63 & 37.61 & 33.60 & 0.0725 & 0.2009 & 5.37 \\
\hline 0.15 & 16.59 & 23.11 & 37.66 & 28.61 & 0.0932 & 0.4364 & 8.32 \\
\hline 0.2 & 16.60 & 24.41 & 37.61 & 25.69 & 0.0928 & 0.4733 & 9.81 \\
\hline
\end{tabular}

climate sensitivities to $\mathrm{CO}_{2}$ doubling ranging from $2.18^{\circ}$ to $9.81^{\circ} \mathrm{C}$ in the $\mathrm{FCM}$ experiments and from $1.95^{\circ}$ to $10.89^{\circ} \mathrm{C}$ in the SOM experiments. The larger the $c$ parameter, the higher the ECS. Note that the ECS estimates for Exp 9 and 10 are the least accurate in comparison to the other runs, because the TOA imbalance is the largest (TOA imbalance is equal to 0.44 and $0.47 \mathrm{~W} \mathrm{~m}^{-2}$ for Exp 9 and 10, respectively). Still, the TOA imbalance in our study is acceptable, and smaller than that used in previous studies to calculate ECS based on model data (Lin et al. 2010; Otto et al. 2013).

The LCC feedback strength scales fairly linearly with the $c$ parameter (Fig. 1b), while global mean SST (Fig. 1a) and ECS (Tables 2 and 3) scale nonlinearly with the $c$ parameter as expected given the inverse relationship between feedback strength and ECS. As a result, the unmodified model's response to a $\mathrm{CO}_{2}$ doubling (Exp 2 and 12; Tables 2 and 3; Figs. 3a and 5a) is more easily amplified by positive $\mathrm{c}$ values than suppressed by negative $c$ values.

\section{b. Transient adjustment}

Here we briefly show the temporal adjustment to an abrupt $\mathrm{CO}_{2}$ doubling within each experiment. The time series of global annual mean SST, LCC, and TOA imbalance for the FCM experiments are shown in
Figs. 2a-c. Two main time scales can be seen in the SST evolution. First, an initial fast time scale $(\sim 100 \mathrm{yr})$ that is an initial abrupt change in SST. This is also seen in the results of Burls et al. (2017, hereafter B17) and Marshall et al. (2015), and is caused by the initial adjustment of the upper ocean (thermocline). The second slow time scale associated with deep ocean adjustment occurs over 1000 years or more (B17). As the $c$ parameter is increased, and the low-cloud feedback strengthens, the rate of change in SST associated with the initial fast adjustment time scale increases. Interestingly, for positive $c$ values, and to some extent the control simulation, there does appear to also be an intermediate time scale of adjustment between years 100 to $\sim 400-600$ depending on the run. Toward the end of the simulations (1800 years), the rate of change in global mean SST is negligible for all cases, except Exp 8. Although the full adjustment of deep ocean for this model is generally obtained after $\sim 3000$ years, such adjustment has minimal effect on equatorial SSTs (Fedorov et al. 2015; B17).

The LCC and TOA imbalance (Figs. $2 b$ and $2 c$ ) shows that all cases (except perhaps Exp 8 for LCC) are well adjusted by the end of $1800-y r$ simulation. The relatively large initial TOA imbalance (near $3 \mathrm{~W} \mathrm{~m}^{-2}$ ), resulting from the abrupt $\mathrm{CO}_{2}$ increase and modified low-cloud response, drops abruptly within the first time scale. By

TABLE 3. As in Table 2, but for SOM simulations.

\begin{tabular}{|c|c|c|c|c|c|c|c|}
\hline \multirow[b]{2}{*}{$c$ parameter } & \multicolumn{2}{|c|}{$\operatorname{SST}\left({ }^{\circ} \mathrm{C}\right)$} & \multicolumn{2}{|c|}{$\operatorname{LCC}(\%)$} & \multicolumn{2}{|c|}{ TOA imbalance $\left(\mathrm{W} \mathrm{m}^{-2}\right)$} & \multirow[b]{2}{*}{$\operatorname{ECS}\left({ }^{\circ} \mathrm{C}\right)$} \\
\hline & Preindustrial $\mathrm{CO}_{2}$ & $2 \times \mathrm{CO}_{2}$ & Preindustrial $\mathrm{CO}_{2}$ & $2 \times \mathrm{CO}_{2}$ & Preindustrial $\mathrm{CO}_{2}$ & $2 \times \mathrm{CO}_{2}$ & \\
\hline No modification & 16.38 & 18.50 & 37.83 & 37.24 & -0.0471 & -0.0459 & 2.91 \\
\hline-0.2 & 16.37 & 17.74 & 37.93 & 39.17 & -0.0451 & -0.0505 & 1.95 \\
\hline-0.15 & 16.37 & 17.86 & 37.89 & 38.79 & -0.0434 & -0.0367 & 2.11 \\
\hline-0.1 & 16.38 & 18.00 & 37.89 & 38.43 & -0.0412 & -0.0465 & 2.27 \\
\hline-0.05 & 16.38 & 18.22 & 37.87 & 37.91 & -0.0490 & -0.0449 & 2.56 \\
\hline 0.05 & 16.42 & 19.16 & 37.74 & 35.91 & -0.0428 & -0.0351 & 3.77 \\
\hline 0.1 & 16.48 & 21.58 & 37.60 & 31.93 & -0.0351 & 0.0480 & 6.78 \\
\hline 0.15 & 16.64 & 24.02 & 37.24 & 27.19 & -0.0409 & 0.0271 & 9.64 \\
\hline 0.2 & 16.81 & 25.13 & 36.72 & 24.85 & -0.0333 & 0.0007 & 10.89 \\
\hline
\end{tabular}



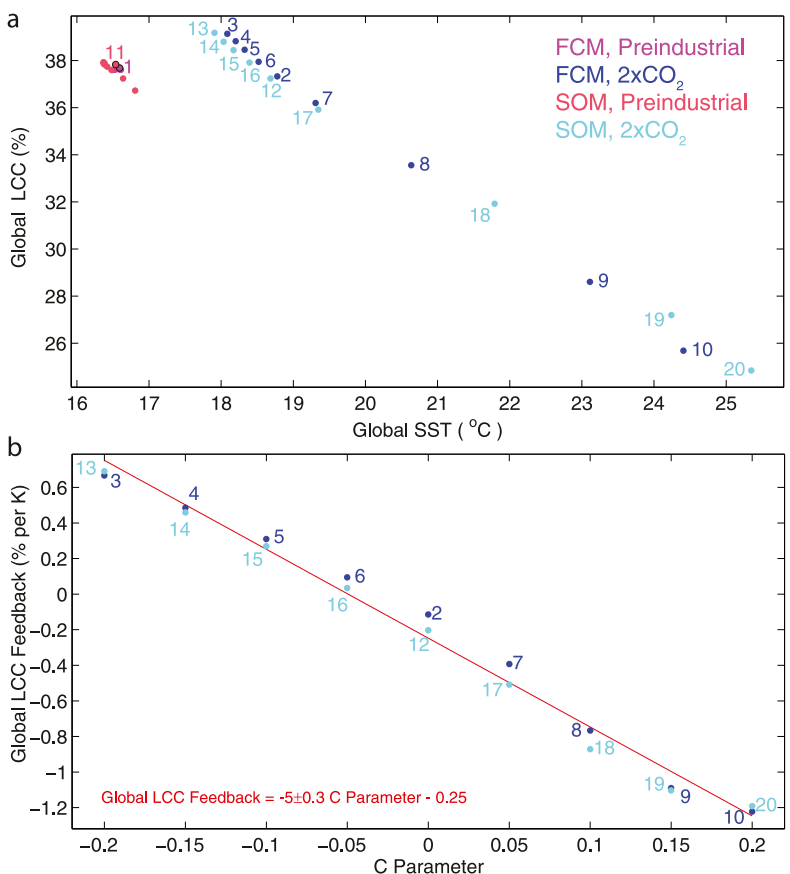

FIG. 1. (a) Annual mean global LCC vs SST for all 36 experiments in this study that are categorized in four groups: FCM with preindustrial $\mathrm{CO}_{2}, \mathrm{FCM}$ with doubled $\mathrm{CO}_{2}$, SOM with preindustrial $\mathrm{CO}_{2}$, and $\mathrm{SOM}$ with doubled $\mathrm{CO}_{2}$. (b) The global mean LCC feedback within each doubled $\mathrm{CO}_{2}$ experiment as a function of the $c$ parameter. The red line and text indicate the least squares fit here and throughout similar figures in the manuscript.

the end of 1800-yr run, the TOA imbalance is less than $0.035 \mathrm{~W} \mathrm{~m}^{-2}$ for $\operatorname{Exp} 2-6$ (negative $c$ values) and equal to $0.07,0.20,0.44$, and $0.47 \mathrm{~W} \mathrm{~m}^{-2}$ for $\operatorname{Exp} 7,8,9$, and 10 respectively (Table 2). It is worth noting that Exp 10 displays a unique adjustment response: after the initial abrupt drop of TOA imbalance to $2 \mathrm{~W} \mathrm{~m}^{-2}$, a rise in imbalance is seen for 200 years, reaching to a maximum of $2.5 \mathrm{~W} \mathrm{~m}^{-2}$. Thereafter, both TOA imbalance and its rate of change decrease. The reason for this rise seems to be associated with the significant rise in SST over this time period (resulting from strong positive feedbacks) as seen in Fig. 2a. Breaking this SST adjustment into regional domains (figure not shown) reveals that the extratropics, particularly between $50^{\circ}$ and $70^{\circ} \mathrm{S}$ in the Southern Ocean contributes the most in the sudden rise in SST within this experiment. The domain-averaged SST analysis shows that the tropics (between $30^{\circ} \mathrm{S}$ and $30^{\circ} \mathrm{N}$ ) adjust the fastest, followed by adjustment in the $\mathrm{NH}\left(0^{\circ}-90^{\circ} \mathrm{N}\right), \mathrm{SH}\left(0^{\circ}-\right.$ $90^{\circ} \mathrm{S}$ ), $\mathrm{SH}$ extratropics (south of $30^{\circ} \mathrm{S}$ ), and the Southern Ocean (between $50^{\circ}$ and $70^{\circ} \mathrm{S}$ ), in agreement with the results of Marshall et al. (2015; see their Fig. 4).

Because of the absence of ocean heat uptake, the SOM experiments demonstrate a very different evolution pattern (Figs. 2d-f), with only the initial time scale corresponding to an abrupt change in SST and LCC within 20-30 years. Thereafter, no drift is seen in SST and LCC, as they are fully adjusted with negligible TOA imbalance (absolute values does not exceed $0.06 \mathrm{~W} \mathrm{~m}^{-2}$; Table 3) 40 years after the start time.

\section{c. Spatial distributions}

Modifying the low-cloud amount feedback strength has regionally distinct implications. The spatial distribution of annual-mean FCM LCC and SST differences, with respect to the ctrl experiment, are shown for a representative subset in Figs. 3 and 4, respectively. The unmodified $2 \times \mathrm{CO}_{2}$ experiment experiences a negative LCC feedback over the high-latitude oceans with a maximum LCC increase of $\sim 20 \%$, as well as over the subtropical stratus cloud deck regions, although the negative feedback here is relatively weak. A positive feedback is seen over the midlatitude ocean, as well as parts of the tropical and subtropical ocean. The decrease in LCC in the midlatitudes and the increase in LCC in the high latitudes appears to be associated with [but not necessarily caused by; see Ceppi et al. (2014) for a discussion of cause vs effect] a poleward shift in the storm tracks (Eastman and Warren 2013; Ceppi et al. 2014; Norris et al. 2016; Shaw et al. 2016), as well as a poleward shift of the Hadley cell (Grise and Polvani 2014; Tselioudis et al. 2016; Lipat et al. 2017). While this is an interesting aspect of our results, given the tropical focus of this study, we defer a thorough investigation of the mid- and high-latitude changes to future work.

In the $c=-0.22 \times \mathrm{CO}_{2}$ experiment the negative LCC feedback in the high-latitude ocean and the stratus cloud deck regions is enhanced while the strength of the positive feedback in the midlatitudes is weakened. As a result, the global LCC is larger than the control acting as a negative radiative feedback and reducing the ECS (Table 2). SST warming is suppressed in this experiment especially in the midlatitude Southern Ocean, as well as the tropical and subtropical eastern Pacific.

Positive $c$ values cause a decrease ( $\sim 30 \%$ for $c=0.15)$ in LCC in the midlatitude oceans, (encroaching on the high-latitude Southern Oceans as $c$ values increase), and the subtropical eastern Pacific and Atlantic. Consequently, warming is enhanced in the midlatitudes $\left(\sim 10^{\circ} \mathrm{C}\right.$ for $c=$ 0.15). The slight increase in LCC over the central Pacific equatorial ocean (e.g., $\sim 5 \%$ for $c=0.15$ ) is due to an increase in shallow convective clouds as SST in the Pacific cold tongue increases $\left(\sim 8^{\circ} \mathrm{C}\right.$ for $\left.c=0.15\right)$, the zonal SST gradient decreases substantially, and tropical convection extends farther eastward. High-level cloud cover also increases in this region (figure not shown), indicating enhanced deep convection. The increase in SST in the Pacific cold tongue $\left(\sim 8^{\circ} \mathrm{C}\right.$ for $\left.c=0.15\right)$ is due to regional 

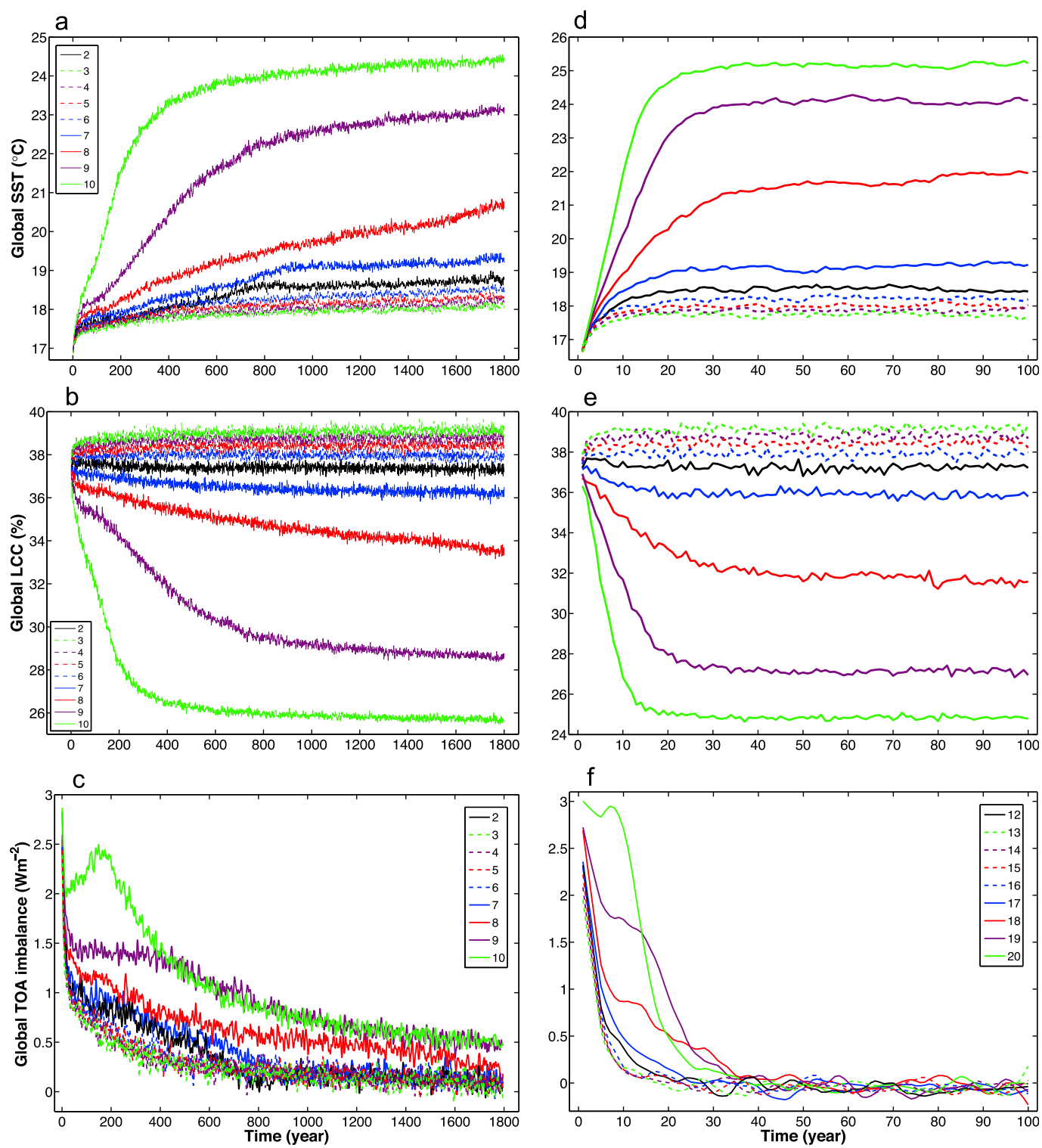

FIG. 2. The time series of (a) annual mean global SSTs, (b) annual mean global LCC, and (c) a 10-yr running mean of the global TOA imbalance for FCM experiments with doubled $\mathrm{CO}_{2}$ level for the entire 1800 -yr run time. (d)-(f) As in (a)-(c), but for SOM experiments for the entire 100 -yr run time.

decreases in LCC, as well as the warming of waters subducted in the extratropics and transported to the equator by the ocean subtropical cells (see section 3e).

Figures 5 and 6 present the annual mean LCC and SST differences with respect to ctrl for the SOM experiments. Overall, the patterns are similar to FCM, but the SOM simulates stronger positive and negative LCC feedback responses for a given $c$ value. The enhancement of both the regional negative feedbacks (when $c$ is set to -0.2 ) and the regional positive feedbacks (when $c$ is set to 0.15) is stronger in the SOM counterpart. As a result, the decrease (increase) in ECS when $c=-0.2(c=0.15)$ is larger in the
SOM (Tables 2 and 3 ) and the regional SST responses are amplified compared to those in the FCM. One important exception to this is the eastern Pacific cold tongue region where the lack of a dynamic ocean component in the SOM experiments excludes the STC warming mechanism active in the FCM experiments (see section 3e).

Figure 7 distills the warming patterns in terms of two important controls on tropical circulation, the zonalmean meridional SST gradient $\left(\Delta T_{\text {meridional }}\right)$ and the zonal SST gradient in the equatorial Pacific $\left(\Delta T_{\text {zonal }}\right)$ as defined in Table 4 . Both of these gradients progressively weaken as low-cloud feedbacks become more positive. 

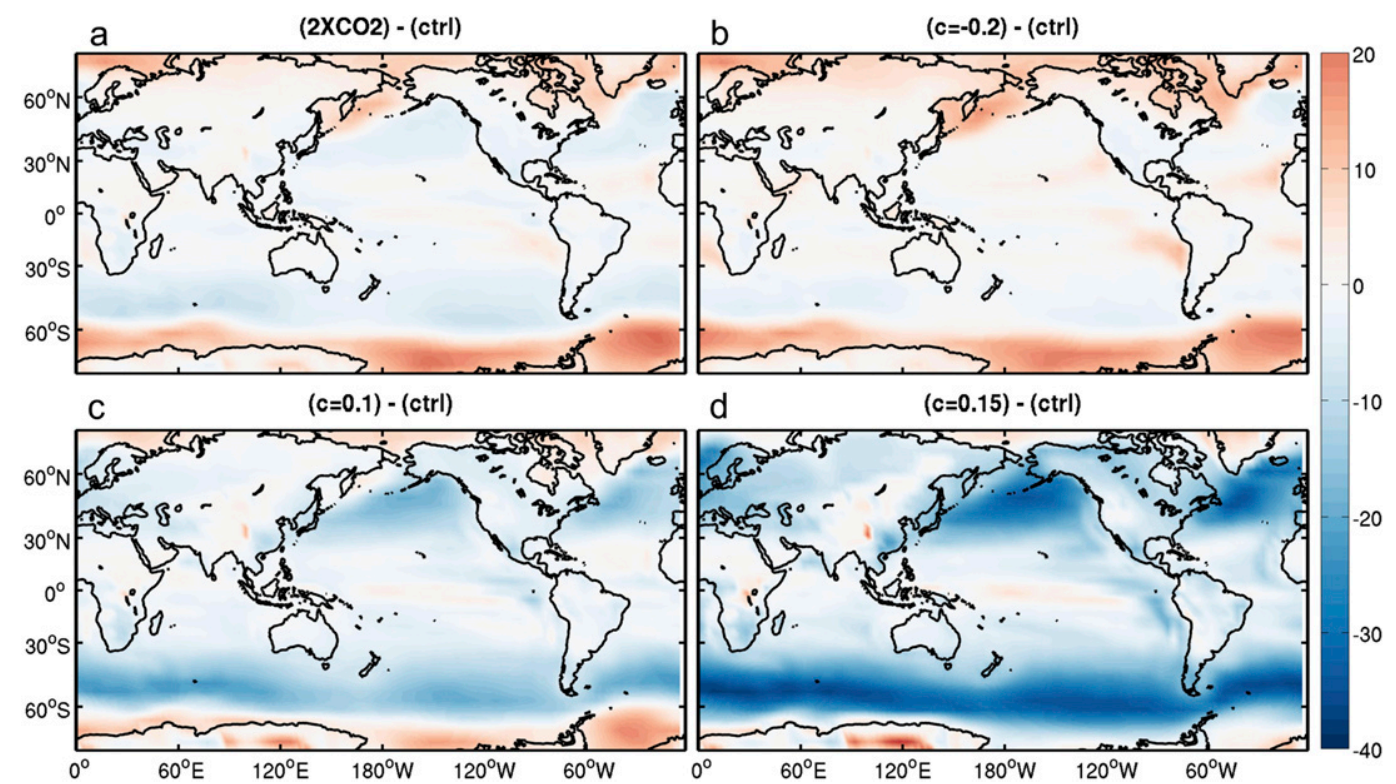

FIG. 3. The annual mean LCC differences with respect to ctrl experiment (Exp 1) for four FCM experiments:

(a) $2 \times \mathrm{CO}_{2}(\operatorname{Exp} 2),(b) c=-0.2(\operatorname{Exp} 3),(c) c=0.1(\operatorname{Exp} 8)$, and (d) $c=0.15(\operatorname{Exp} 9)$. The LCC is unitless $(\%)$.

We will now discuss the relationship between key feature of tropical climate and these weakening meridional and zonal gradients in sections $3 \mathrm{~d}$ and $3 \mathrm{e}$ respectively.

\section{d. Meridional gradients}

\section{1) StRuctural CLIMATE SENSITIVITY}

We refer to changes in the meridional SST gradient as the structural climate sensitivity, an important factor that acts together with ECS in characterizing the hydrological response to global warming (e.g., Burls and Fedorov 2017). Zonal mean SST anomalies with respect to the ctrl are shown for the FCM experiments in Fig. 8a. Warming is the strongest in the midlatitudes in both hemispheres $\left(50^{\circ}-60^{\circ} \mathrm{N} / \mathrm{S}\right)$ where LCC decreases the most. Tropical warming also increases with $c$ but is muted by comparison such that the larger the $c$ parameter, the weaker the meridional SST gradient (Fig. 7a).
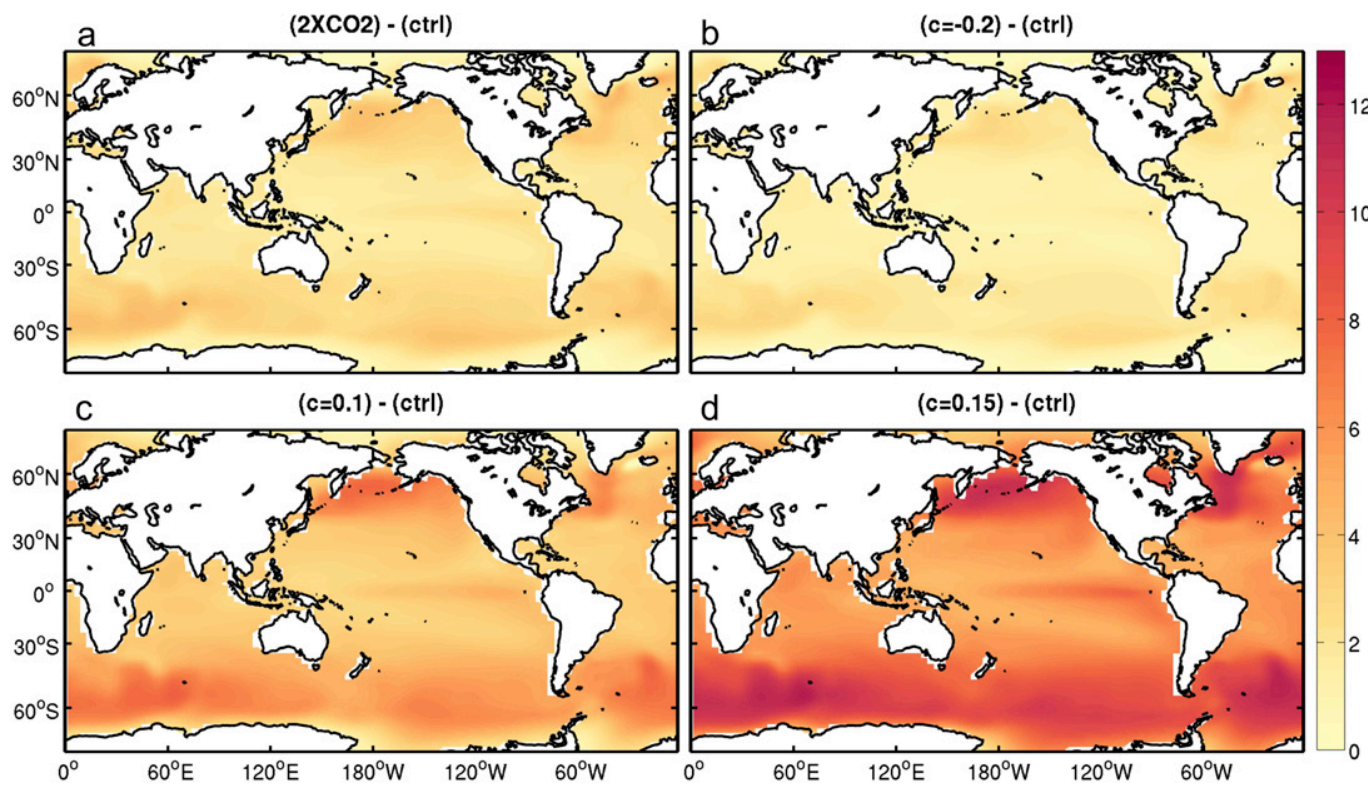

FIG. 4. As in Fig. 3, but for SST. The SST unit is ${ }^{\circ} \mathrm{C}$. 

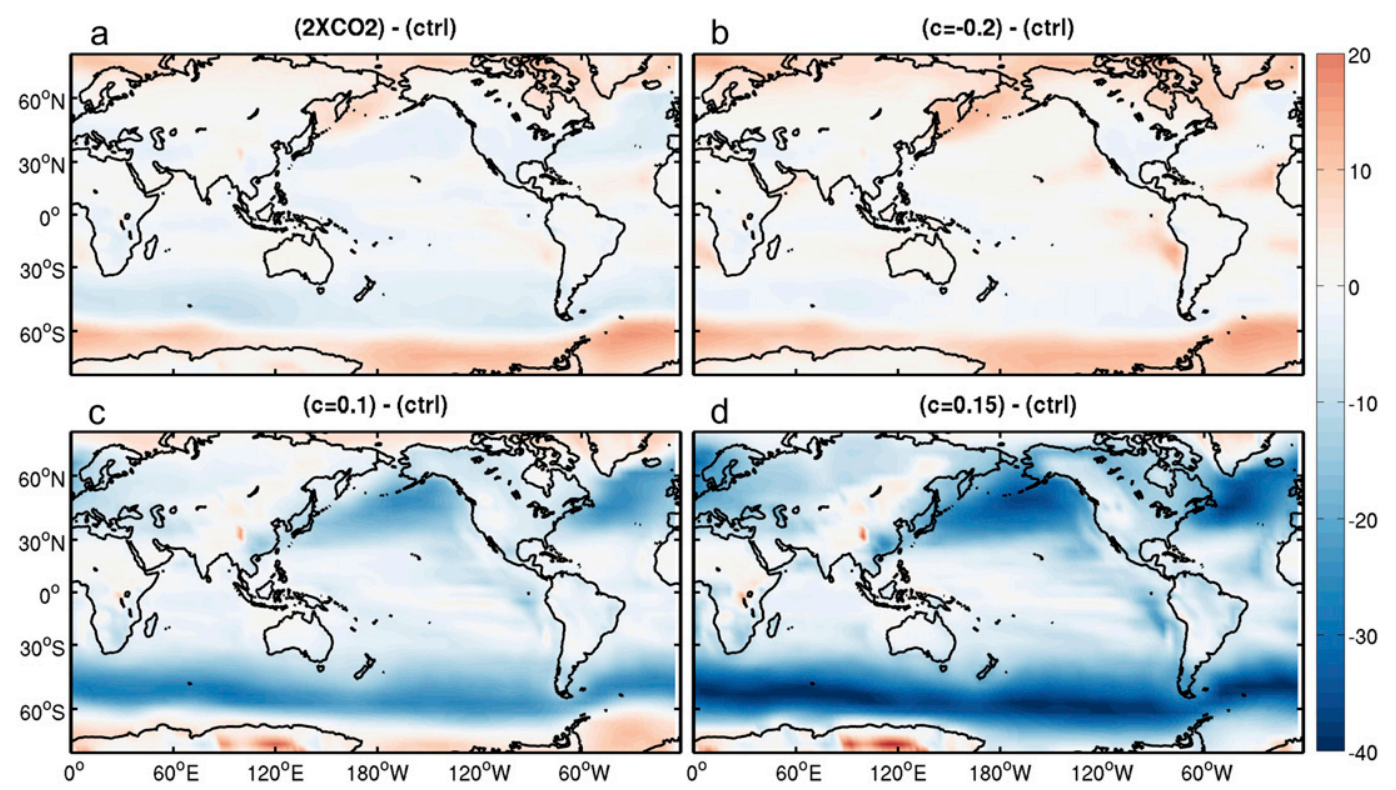

FIG. 5. The annual mean LCC differences with respect to ctrl experiment (Exp 11) for four SOM experiments: (a) $2 \times \mathrm{CO}_{2}(\operatorname{Exp} 12),(b) c=-0.2(\operatorname{Exp} 13),(c) c=0.1(\operatorname{Exp} 18)$, and $(\mathrm{d}) c=0.15(\operatorname{Exp} 19)$. The LCC is unitless $(\%)$.

For a given positive $c$ value, the SOM experiments have a weaker meridional SST gradient. This is the result of warmer midlatitude SST anomalies relative to the FCM experiments (Fig. 8b), due to enhanced LCC decreases (Fig. 3 vs Fig. 5), and because the poleward ocean heat transport remains fixed while it decreases at most latitudes (Figs. 8c and 8d) across the FCM experiments. As a result, the sensitivity of meridional SST gradients to warming is weaker in the FCM simulation than the SOM simulations (Fig. 7a). Note however that the opposite is true for the zonal SST gradients (Fig. 7b), once again due to the ocean heat transport response discussed in section $3 \mathrm{e}$.

The progressive weakening of poleward ocean heat transport by the wind-driven ocean STCs across the FCM experiments (Figs. 8c and 8d) is due to the

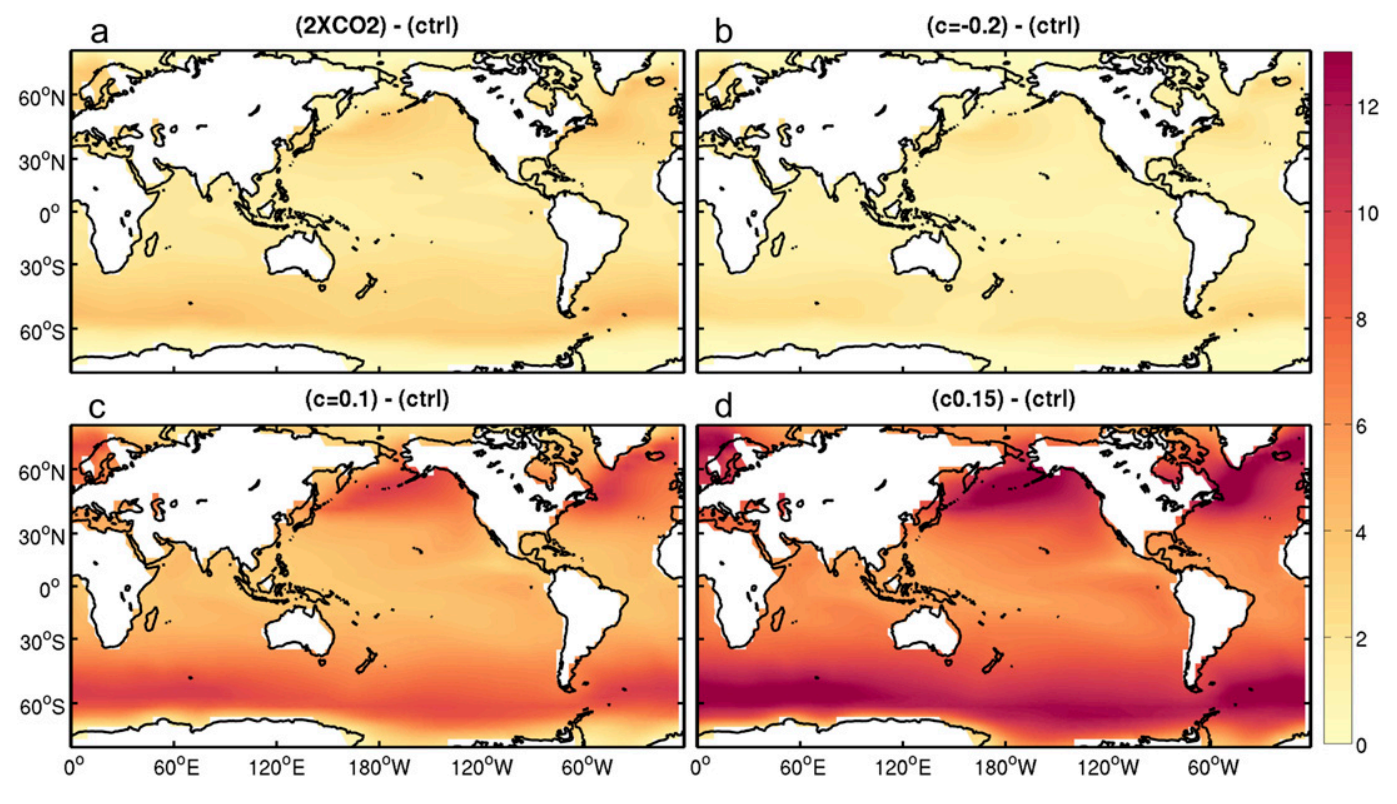

FIG. 6. As in Fig. 5, but for SST. The SST unit is ${ }^{\circ} \mathrm{C}$. 

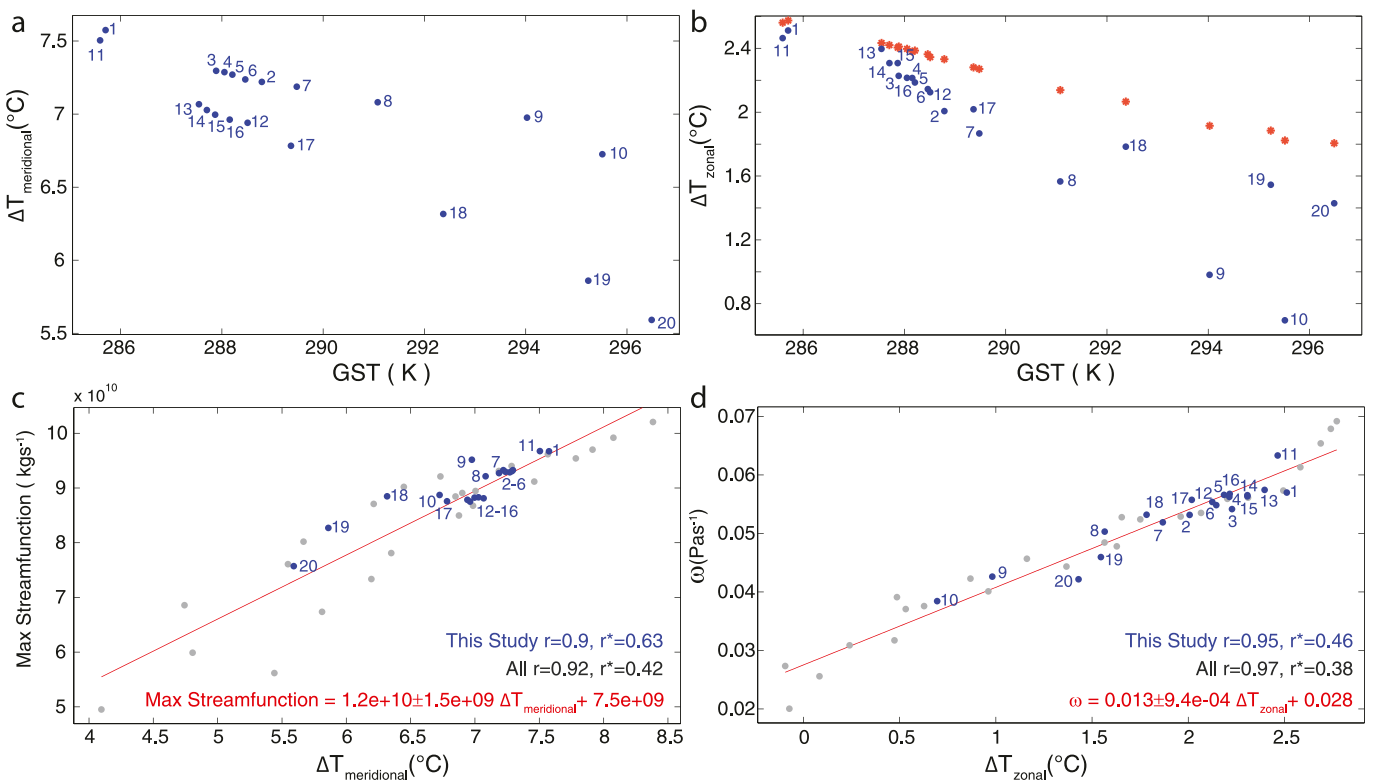

FIG. 7. (a) The meridional SST gradient $\left(\Delta T_{\text {meridional }}\right)$ vs global mean surface temperature (GST), (b) the equatorial Pacific zonal SST gradient ( $\Delta T_{\text {zonal }}$ ) vs GST, (c) Hadley strength vs $\Delta T_{\text {meridional }}$, and (d) Walker strength vs $\Delta T_{\text {zonal }}$. The experiments with doubled $\mathrm{CO}_{2}$ levels for FCM (Exp 2-10) and SOM (Exp 12-20) are shown here by blue dots together with their respective control simulations Exp 1 (11). The red dots in (b) indicate the scaling of MS11. See Table 4 for the definition of $\Delta T_{\text {zonal }}$ and $\Delta T_{\text {meridional }}$, and see the text for the definition of Hadley strength and Walker strength. The light gray dots show results from the abrupt $\mathrm{CO}_{2}$ and modified cloud albedo experiments of Burls and Fedorov (2014a) and Fedorov et al. (2015) for comparison. Also, $r$ indicates the correlation between variables, and $r^{*}$ the required correlation value for significance at the $95 \%$ level based on a Student's $t$ test taking into account the effective degrees of freedom.

weakening meridional SST gradient. Consistent with the results and theory discussed in Burls and Fedorov (2014a) and Fedorov et al. (2015), a weaker meridional SST gradient acts to reduces both the meridional temperature gradient component of temperature advection by the STCs, as well as their strength by weakening the Hadley circulation (Fig. 7c). The maximum of the mean atmospheric meridional streamfunction is used as a measure of the Hadley cell strength. It is the maximum in the hemisphere where the Hadley circulation is strongest. This way of quantifying changes in the strength of the Hadley circulation includes the effects of both the local meridional gradient in the hemisphere in which the Hadley circulation is the strongest, as well as the temperature difference between hemispheres, since both affect the strength of Hadley cell (Broccoli et al. 2006; Kang et al. 2008). However, the latter effect is secondary, given the structure of the meridional SST changes, as shown in Fig. 8.

\section{2) The HydrologicAl CYCLE RESPONSE}

Figure 9a shows the zonal mean of precipitation minus evaporation $(P-E)$ anomalies with respect to the ctrl for the FCM experiments. The strongest anomalies occur between $\sim 15^{\circ} \mathrm{S}$ and $15^{\circ} \mathrm{N}$ due to a southward shift in the intertropical convergence zone (ITCZ), largely in the Pacific as illustrated by Fig. 9c. While similar shifts occur in the SOM simulations (Fig. 9b) they are muted in comparison, as illustrated by Fig. 9d. This is associated with a reduced zonal SST gradient response in the SOM simulations relative to the FCM simulations (Fig. 7b).

Subtropical drying between $\sim 10^{\circ}-30^{\circ} \mathrm{N} / \mathrm{S}$ occurs across all the experiments (Fig. 9). As discussed in Burls and Fedorov (2017), from a zonal-mean perspective, subtropical $P-E$ changes are controlled by two competing factors: 1) global warming-induced specific humidity changes that act to enhance subtropical moisture divergence [following the thermodynamic scaling of Held and Soden (2006), generally referred to as the wetgets-wetter dry-gets-drier mechanism] and 2) the relaxation of the meridional SST gradient that acts to reduce the strength of atmospheric meridional Hadley circulation and hence subtropical moisture divergence. To evaluate the relative contribution of these two mechanisms, and the extent to which they are related to global mean and meridional temperature changes, we present in Fig. 10 the same decomposition as shown in Burls and Fedorov (2017, their Fig. 5). The range of meridional gradient changes seen across the set of experiments present in this study (Fig. 10b) is less than 
TABLE 4. Definition of the temperature, albedo, and flux gradients in the experiments.

\begin{tabular}{|c|c|c|c|}
\hline Gradient & Notation & Depth average & Definition \\
\hline Zonal SST gradient & $\Delta T_{\text {zonal }}$ & $0 \mathrm{~m}$ & $\begin{array}{l}\text { Difference between mean SST within the western equatorial } \\
\text { Pacific warm pool }\left(8^{\circ} \mathrm{S}-8^{\circ} \mathrm{N}, 130^{\circ}-205^{\circ} \mathrm{E}\right) \text { and mean SST within } \\
\text { the eastern Pacific cold tongue }\left(8^{\circ} \mathrm{S}-8^{\circ} \mathrm{N}, 205^{\circ}-280^{\circ} \mathrm{E}\right) \text {. }\end{array}$ \\
\hline Meridional SST gradient & $\Delta T_{\text {meridional }}$ & $0 \mathrm{~m}$ & $\begin{array}{l}\left|\left\langle[\mathrm{SST}(\Theta)]-\left[\mathrm{SST}_{\text {equ }}\right]\right\rangle\right| \text {, where the angle brackets indicate the } \\
\text { average value between } 5^{\circ} \text { and } 50^{\circ} \mathrm{N} / \mathrm{S} \text {, the square brackets indicate } \\
\text { the zonal mean, and } \mathrm{SST}_{\text {equ }} \text { is the SST mean between } 5^{\circ} \mathrm{N} \text { and } 5^{\circ} \mathrm{S} \text {. } \\
\text { Each latitudinal circle receives equal weight in this calculation. }\end{array}$ \\
\hline Zonal flux gradient & $\Delta F_{\text {zonal }}$ & $0 \mathrm{~m}$ & $\begin{array}{l}\text { Difference between mean flux within the western equatorial Pacific } \\
\text { warm pool }\left(8^{\circ} \mathrm{S}-8^{\circ} \mathrm{N}, 130^{\circ}-205^{\circ} \mathrm{E}\right) \text { and mean flux within the } \\
\text { eastern Pacific cold tongue }\left(8^{\circ} \mathrm{S}-8^{\circ} \mathrm{N}, 205^{\circ}-280^{\circ} \mathrm{E}\right) \text {. }\end{array}$ \\
\hline $\begin{array}{l}\text { Zonal upper ocean temperature } \\
\text { gradient }\end{array}$ & $\Delta T_{\text {uo,zonal }}$ & $50 \mathrm{~m}$ & $\begin{array}{l}\text { The difference in mean upper-ocean temperature between the } \\
\text { western tropical Pacific }\left(8^{\circ} \mathrm{S}-8^{\circ} \mathrm{N}, 130^{\circ}-205^{\circ} \mathrm{E}\right) \text { and the eastern } \\
\text { tropical Pacific }\left(8^{\circ} \mathrm{S}-8^{\circ} \mathrm{N}, 205^{\circ}-280^{\circ} \mathrm{E}\right) \text {. }\end{array}$ \\
\hline $\begin{array}{l}\text { Meridional upper ocean } \\
\text { temperature gradient }\end{array}$ & $\Delta T_{\text {uo,meridional }}$ & $50 \mathrm{~m}$ & $\begin{array}{l}\text { Difference between mean tropical }\left(8^{\circ} \mathrm{S}-8^{\circ} \mathrm{N}, 130^{\circ}-280^{\circ} \mathrm{E}\right) \text { and extra- } \\
\text { tropical Pacific }\left(25^{\circ}-65^{\circ} \mathrm{N} / \mathrm{S}\right) \text { upper ocean temperature. }\end{array}$ \\
\hline Meridional albedo gradient & $\Delta \alpha_{\text {meridional }}$ & TOA & $\begin{array}{l}\text { The difference between extratropical }\left(8^{\circ}-65^{\circ} \mathrm{N} / \mathrm{S}\right) \text { and tropical } \\
\left(8^{\circ} \mathrm{S}-8^{\circ} \mathrm{N}\right) \text { albedo within the Pacific basin. }\end{array}$ \\
\hline
\end{tabular}

those presented in Burls and Fedorov (2017), while the range in global mean surface warming is comparable (Fig. 10a). As a result, global warming dominates the subtropical $P-E$ response, preventing it from increasing in any of these experiments because the dynamic term is never strong enough to overcome the thermodynamic term. Nevertheless, the relationships between these competing terms and global mean and meridional temperature changes still holds (Figs. 10c,d).

\section{e. The equatorial Pacific zonal surface temperature gradient}

To illustrate the impact of cloud feedbacks and ocean coupling on the zonal gradient in equatorial Pacific SSTs, SST is averaged along the equator (from $8^{\circ} \mathrm{S}$ to $8^{\circ} \mathrm{N}$ ) and depicted in Fig. 11. Observed SSTs are $\sim 29^{\circ} \mathrm{C}$ in western Pacific and decrease toward east, falling to $\sim 25^{\circ} \mathrm{C}$ in the eastern Pacific. The ctrl suffers from the well-known cold tongue bias in climate models, simulating SSTs that are too cold by $\sim 2^{\circ} \mathrm{C}$ from $160^{\circ}$ to $260^{\circ} \mathrm{E}$ (Wang et al. 2014; B17). Overall, the annual global mean SST in the ctrl is $\sim 1.5^{\circ} \mathrm{C}$ colder than that in HadISST observations. Nevertheless, we are interested in how the strength of the low-cloud feedback response to a $\mathrm{CO}_{2}$ doubling influences equatorial Pacific SSTs and consequently the zonal SST gradient-a key feature controlling Walker circulation strength and ENSO.

A larger $c$ parameter corresponds to warmer equatorial SSTs. Warming in the FCM is as much as $4^{\circ} \mathrm{C}\left(6^{\circ} \mathrm{C}\right)$ in the western Pacific (eastern Pacific) in the $c=0.2$ simulation. In addition, the west-east SST gradient progressively weakens as $c$ is increased (Fig. 7a). For the SOM experiments (Fig. 11b) equatorial Pacific SSTs respond similarly to the FCM experiments, but for a given $c$ parameter, the SOM Exp 17-20 simulate warmer SSTs in the western Pacific, compared to the FCM. Furthermore, for a given $c$ value the zonal SST gradient is stronger in the SOM experiments, compared to the FCM cases (Fig. 7b), the reasons for which are discussed below. In both sets of experiments the Walker circulation strength is well correlated with the strength of the zonal SST gradient [Fig. 7d; the maximum deviation in ascending pressure velocity (between $130^{\circ} \mathrm{E}$ and $90^{\circ} \mathrm{W}$ ) from zonal mean values (averaged between $10^{\circ} \mathrm{S}$ and $10^{\circ} \mathrm{N}$ ) is used as a measure of the Walker cell].

To evaluate the mechanisms determining the zonal SST gradient response and why the weakening is larger in the FCM experiments, it is helpful to consider the east-west asymmetry in the surface energy fluxes [net SW radiation, net longwave (LW) radiation, latent heat, sensible heat, and the net flux] along the equatorial Pacific and how they change across the experiments (Fig. 12). The net flux is calculated to balance the surface energy budget (net flux $+\mathrm{SW}+\mathrm{LW}+$ latent + sensible $=0)$. Note that the surface fluxes are defined here as positive when they are downward (energy is absorbed by the surface), while the net flux represents the balancing oceanic $Q$ flux and is positive upward. The net flux is equal to the oceanic heat transport in the FCM experiments and the prescribed $Q$ flux, which is fixed across the SOM experiments. There is a strong gradient in the net flux between the western and eastern equatorial Pacific due primarily to the latent and SW components (Figs. 12a,b).

To evaluate the changes in this east-west gradient across the simulations an index is calculated using the 

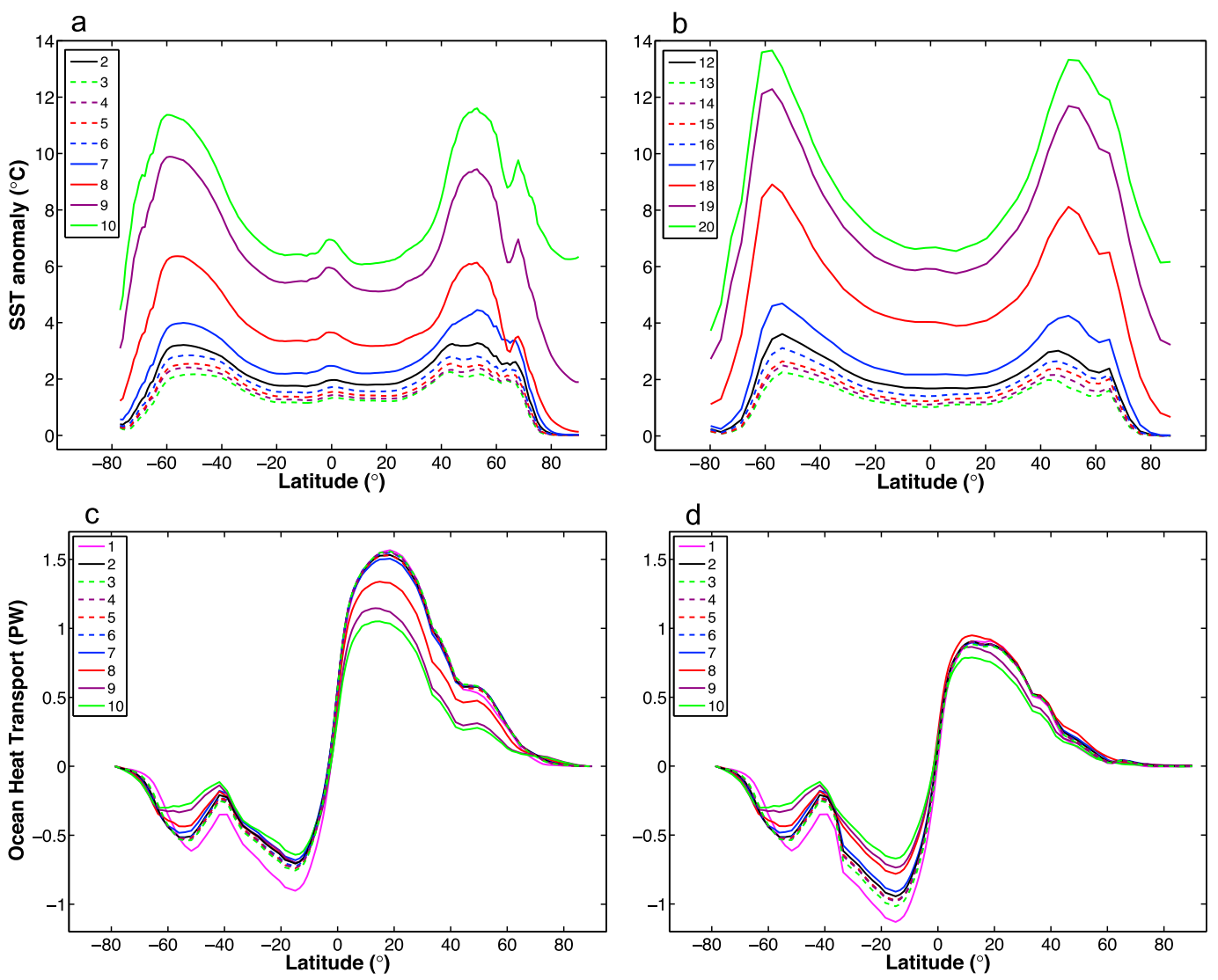

FIG. 8. The annual zonal mean of (a) SST anomaly with respect to ctrl for FCM experiments. (b) As in (a), but for SOM experiments. (c) The annual zonal mean of poleward ocean heat transport for FCM experiments. (d) As in (c), but averaged over Indian and Pacific Oceans. Note that (c) and (d) do not show the anomaly.

regions defined in Table 4 and shown in Figs. 12c and 12d. The net SW is the strongest and the only positive flux; however, its zonal gradient is negative $\left(-24 \mathrm{~W} \mathrm{~m}^{-2}\right.$ for Exp 1) because of the larger cloud amount in the western Pacific, which reduces the surface net SW flux. The zonal gradient in the latent heat flux is also negative $\left(-22 \mathrm{~W} \mathrm{~m}^{-2}\right.$ for Exp 1) because warmer SSTs in the western Pacific lead to a stronger evaporative flux toward the atmosphere. The net LW flux and sensible heat fluxes are rather weak (values roughly equal to -50 and $-10 \mathrm{Wm}^{-2}$, respectively, for Exp 1) and only change slightly from western Pacific to eastern Pacific. Their zonal gradients are very small (less than $5 \mathrm{Wm}^{-2}$ ) and cancel each other. Therefore, the zonal gradient in the net flux is balanced primarily by the net SW and latent heat flux gradients. The energy fluxes in SOM ctrl (Fig. 12b) are similar to those in FCM ctrl. This is expected, because the prescribed $Q$ flux used in SOM is calculated from the $Q$ flux in the FCM ctrl. In contrast to the FCM simulations however, the net flux in the SOM, by design, cannot change (Fig. 12d) and its zonal gradient remains near $50 \mathrm{~W} \mathrm{~m}^{-2}$.
The zonal SST gradient scaling with tropical warming predicted by the MS11 scaling [MS11, their Eq. (8); explained in section 1b] has been added to Fig. 7b. Note that following MS11 the time- and Pacific-mean surface temperature averaged within $8^{\circ} \mathrm{S}-8^{\circ} \mathrm{N}$ was used for each experiment to calculate the derivative of the saturation specific humidity with respect to temperature [global mean surface temperature (GST) values are however shown on the $x$ axis of Fig. 7b]. The east-west saturation specific humidity difference was held fixed to the FCM and SOM control value, respectively. In our SOM experiments, the $Q$ flux is also invariant, but the presence of clouds provides an extra degree of freedom. Note that the summation of latent heat gradient and net SW gradient (equal to a negative net flux gradient) is invariant (Fig. 12d). However, the zonal SST gradient decreases more in our SOM experiments than predicted by the MS11 scaling (Fig. 7b) because cloud-induced changes in the net SW gradient act to further reduce the zonal SST gradient, allowing the latent heat flux gradient to relax further toward zero than it would in the absence of clouds (Fig. 12d). The enhancement of the net SW 

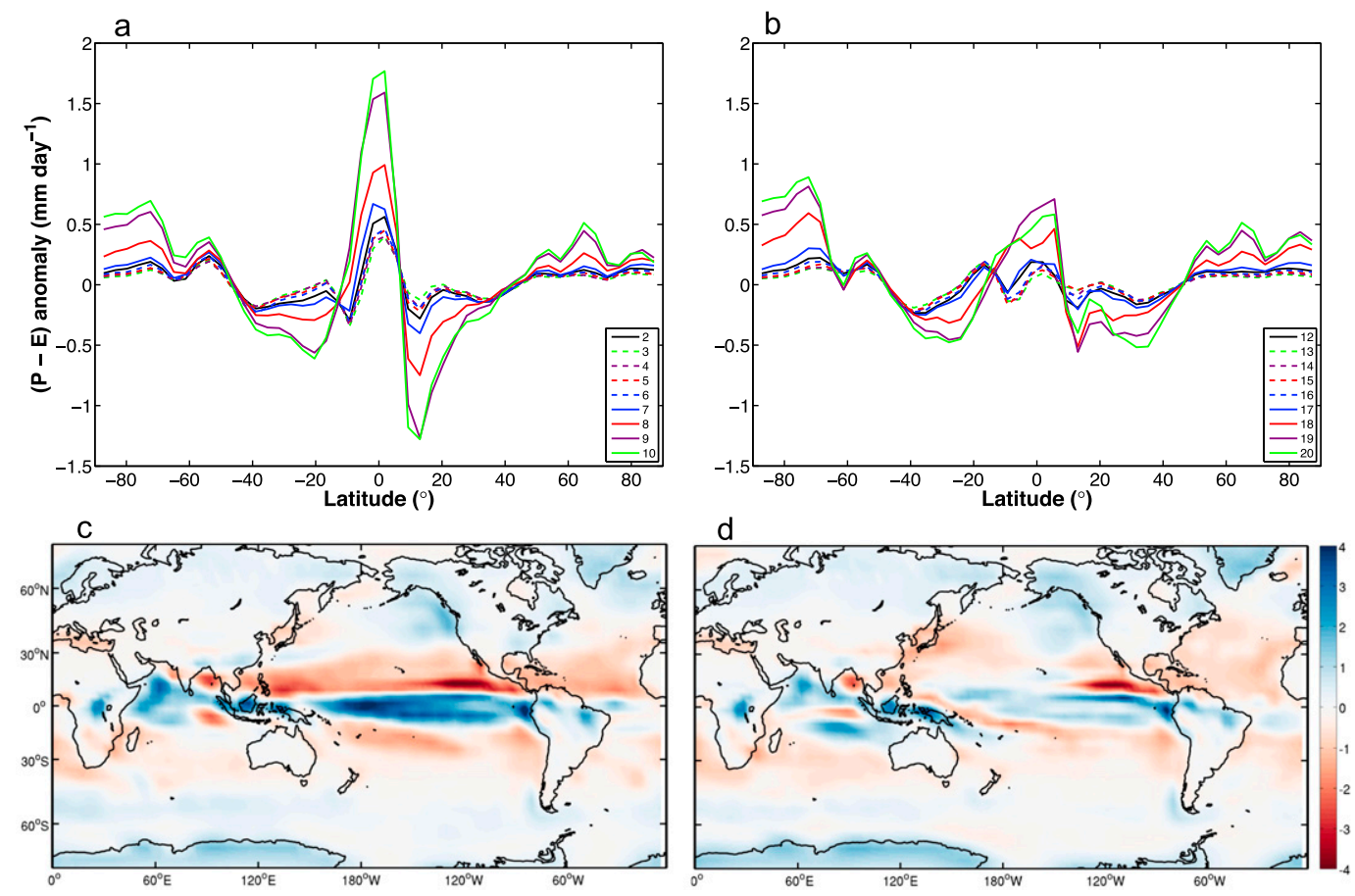

FIG. 9. (a) The annual zonal mean of the $P-E$ anomaly with respect to ctrl for FCM experiments. (b) As in (a), but for SOM experiments. (c) The annual mean of $P-E$ difference with respect to ctrl (Exp 1) for FCM experiment $c=0.15$ (Exp 9). (d) The annual mean of $P-E$ difference with respect to $\operatorname{ctrl}$ (Exp 11) for SOM experiment $c=$ $0.15(\operatorname{Exp} 19)$.

gradient is caused by a decrease in LCC and an increase in the net SW flux in the equatorial eastern Pacific.

For the FCM simulations, on the other hand, the net SW and latent heat gradients both weaken (especially Exp 8-10) as the net flux can change, and as a result the zonal SST gradient changes are larger. This is associated with enhanced surface warming in the eastern Pacific relative to the western Pacific driven largely by reduced ocean cooling. Consequently, cloud amount increases in the eastern Pacific, reducing the net surface SW flux and weakening the net SW gradient. This enhanced eastern Pacific warming also acts to enhance the latent heat flux, leading to a weakened latent heat flux gradient. This difference between the SOM and FCM due to the coupling between ocean dynamics and the SW response of equatorial clouds is consistent with differences in their equatorial precipitation changes seen in Fig. 9c versus Fig. 9d.

Burls and Fedorov (2014a) and Fedorov et al. (2015) find that the zonal gradient in upper-ocean (the upper $50 \mathrm{~m}$ ) temperature scales with the meridional upperocean temperature gradient and TOA albedo gradient. The relationship between the upper-ocean meridional and zonal temperature gradients [presented by Fedorov et al. (2015); explained in section 1b] and the relationship between the upper-ocean zonal temperature gradient and the meridional TOA albedo gradient [presented by Burls and Fedorov (2014a); explained in section 1b] hold across our FCM experiments as shown in Figs. 13a and 13b, respectively. Following the simple LH97 box model, LCC decreases across our FCM experiments and results in the temperature of water subducted in the extratropics and transported to the equator by the wind-driven ocean STCs increasing. This in turn gives rise to the equatorial surface heat flux changes seen in Fig. 12c that are prohibited in the SOM experiments.

Although not shown, it is worth noting that the slope of the relationship between the zonal SST gradient and the meridional SST gradient (as opposed to the upper ocean gradients shown in Fig. 13), using the same definitions, is steeper than in Fig. 3a of Fedorov et al. (2015), with a slope of $3^{\circ} \pm 0.74^{\circ} \mathrm{C}^{\circ} \mathrm{C}^{-1}$ across our FCM when evaluating the SST gradients. We hypothesize that this increased sensitivity of SST gradients despite the similar sensitivity of upper ocean temperature gradients is due to the enhanced ratio of global warming relative to meridional gradient weakening seen across our FCM experiments and the local effects of modifying the low-cloud feedback strength in the equatorial region across our simulations. The zonal SST gradient changes in our FCM experiments experience the combined gradient weakening effects of 1 ) the dynamically driven weakening 

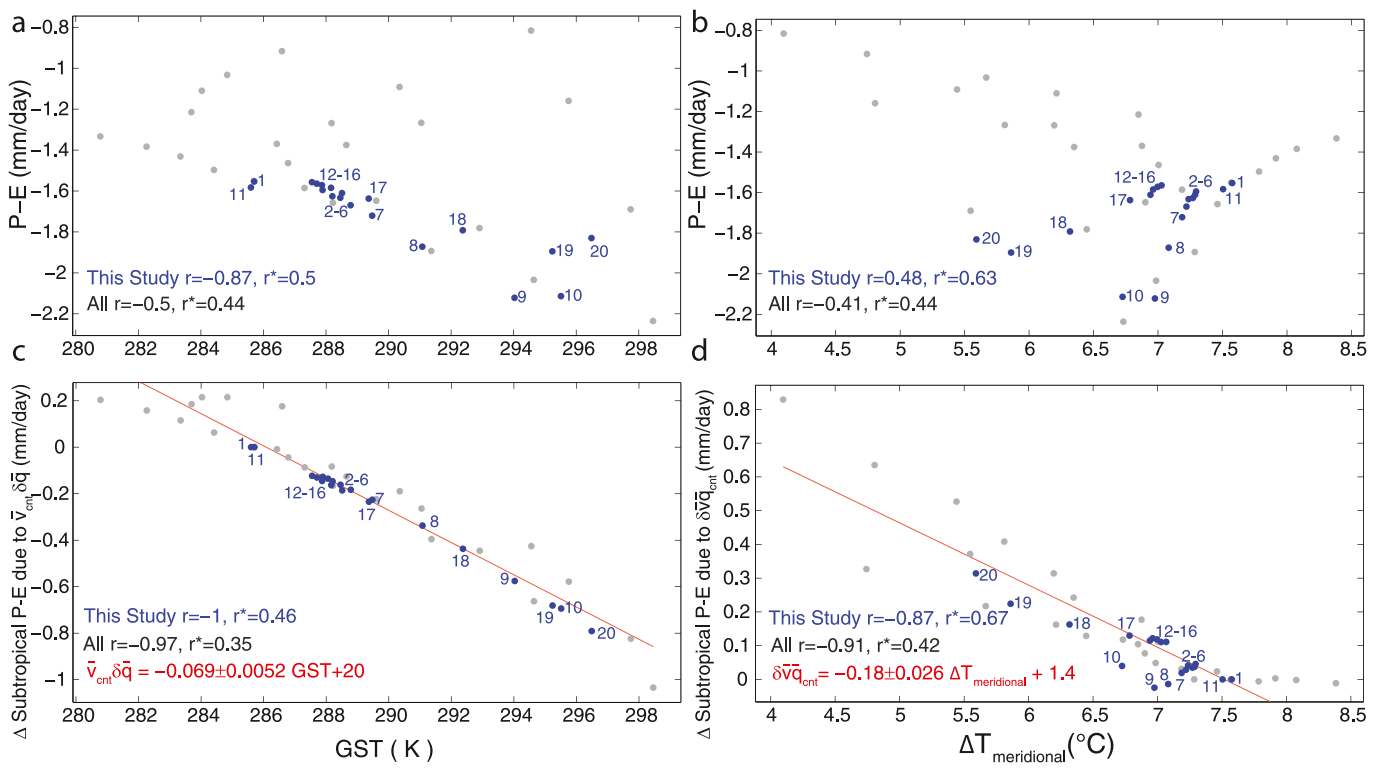

FIG. 10. Zonal-mean subtropical $\left(10^{\circ}\right.$ and $\left.30^{\circ} \mathrm{N} / \mathrm{S}\right) P-E$ across the FCM and SOM experiments (blue) as a function of (a) GST and (b) the meridional SST gradient. (c) The relationship between GST and the change in subtropical $P-E$ due to humidity-induced changes in the time-mean moisture transport $\left(\bar{v}_{\mathrm{cnt}} \delta \bar{q}\right)$ and (d) the relationship between the meridional SST gradient and the change in subtropical $P-E$ due to circulation-induced changes in the time-mean moisture transport $\left(\delta \bar{v} \bar{q}_{\text {cnt }}\right)$. The gray dots indicate the Burls and Fedorov (2017) sensitivity experiments for comparison (see their Fig. 5). The term $\bar{q}$ is the time-mean atmospheric specific humidity, and $\bar{v}$ the time-mean horizontal wind vector integrated across pressure levels from the bottom to the top of the troposphere. The "cnt" subscript indicates control values and $\delta$ deviations from the control. The perturbation term $(\delta \bar{v} \delta \bar{q})$ is not shown, with a contribution that is secondary but not negligible-particularly in the experiments where the meridional gradient is weak. The eddy contribution $\left(\overline{v^{\prime} q^{\prime}}\right)$ is small and not shown. See Burls and Fedorov (2017) for further details on this diagnostic approach and the caption of Fig. 7 herein for the definitions of $r$ and $r^{*}$.

of the upper-ocean meridional temperature gradients set by the box model (Fig. 13a) and 2) the thermodynamically driven evaporative damping effect acting together with the modified LCC feedback to set the weakening of the zonal SST gradient even in the absence of ocean dynamics (the SOM experiments in Fig. 7b). The latter effect occurs in the absence of ocean dynamic and is enhanced in our experiments by our modifications to the low-cloud feedback strength across our simulations.

\section{Conclusions}

The spread in ECS across climate models has not narrowed despite decades of research on the topic
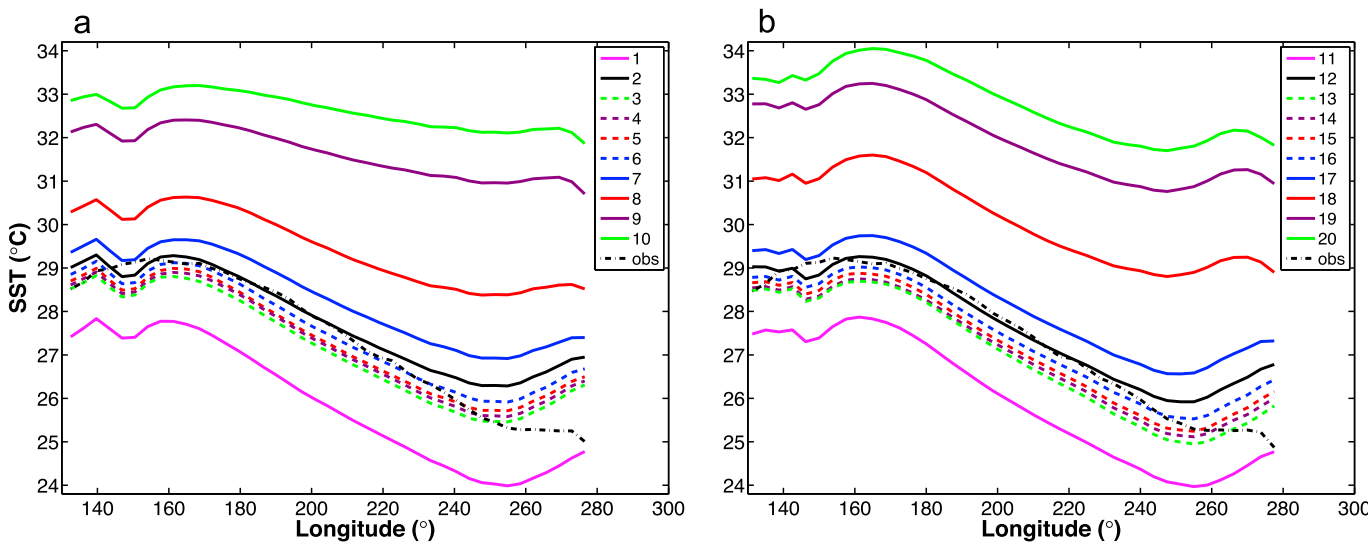

FIG. 11. (a) Annual mean SSTs in the Pacific averaged along the equator $\left(8^{\circ} \mathrm{S}-8^{\circ} \mathrm{N}\right)$ for observations (HadISST) and for FCM experiments with doubled $\mathrm{CO}_{2}$ level. (b) As in (a), but for SOM experiments. 

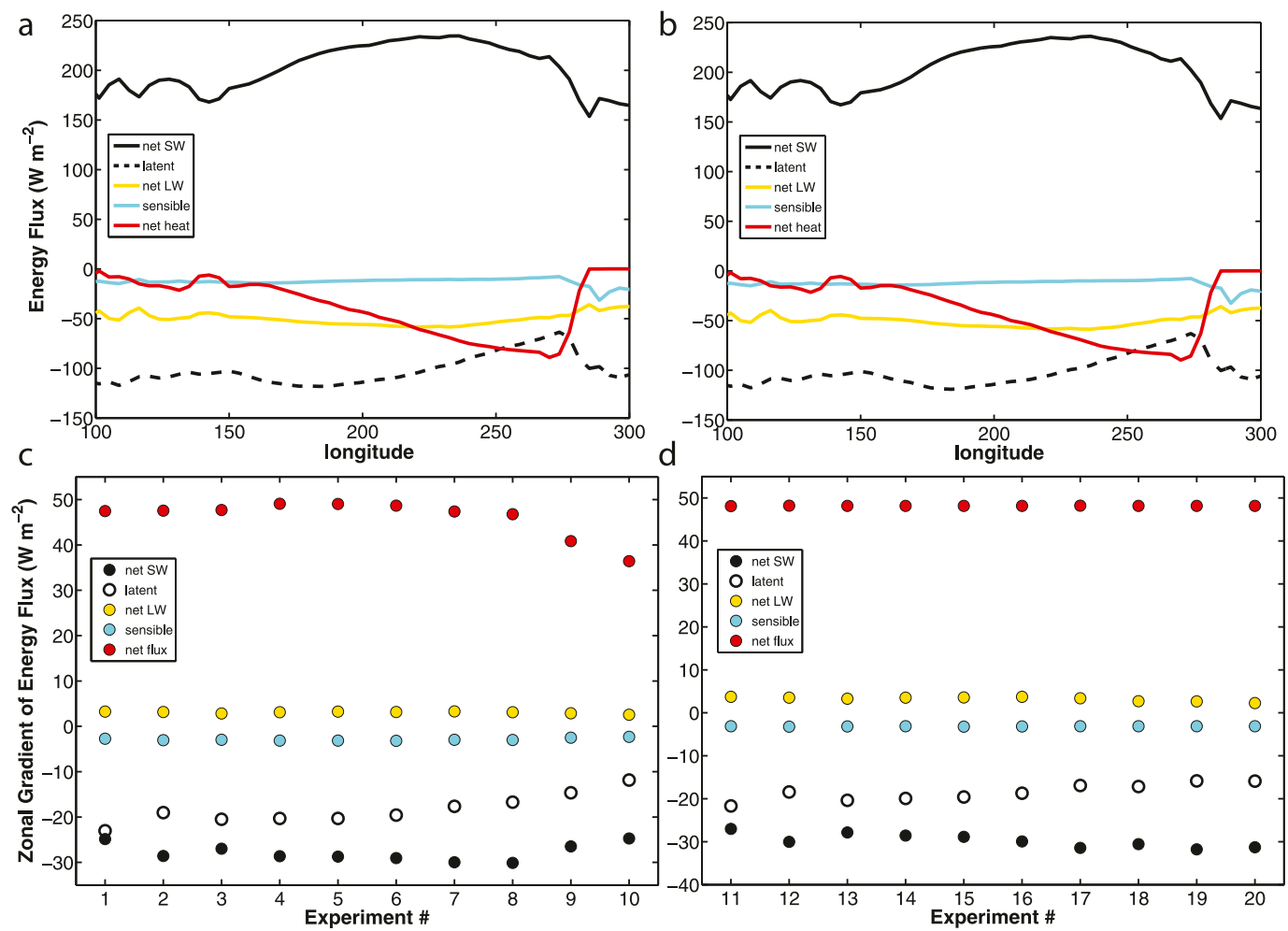

FIG. 12. (a) Annual mean surface energy fluxes in the Pacific averaged along the equator $\left(8^{\circ} \mathrm{S}-8^{\circ} \mathrm{N}\right)$ for FCM ctrl (Exp 1). (b) As in (a), but for SOM ctrl (Exp 11). (c) Zonal gradient in the surface energy fluxes for the FCM experiments. (d) As in (c), but for SOM experiments. The experiment number is shown on $x$ axis for (c) and (d). See Table 4 for the definition of the zonal gradient.

(Boucher et al. 2013). The spread is due primarily to uncertainty in the sign and magnitude of cloud feedbacks, in particular low-cloud feedbacks (IPCC 2013). To isolate the influence low-cloud feedback strength has on tropical climate change, we perform a suite of FCM and SOM climate simulations across which we systematically modify the low-cloud feedback strength within a single model by modifying the stratus cloud fraction so that it is a function of not only local conditions but also global SST in a series of abrupt $2 \times \mathrm{CO}_{2}$ sensitivity experiments. We control the strength and sign of cloud feedback using an arbitrary parameter $c$ [see Eq. (1)] that varies from -0.2 (negative feedback) to 0.2 (strong positive feedback).

Doubling $\mathrm{CO}_{2}$ leads to a decrease in global LCC in our unperturbed control simulation. This decrease in
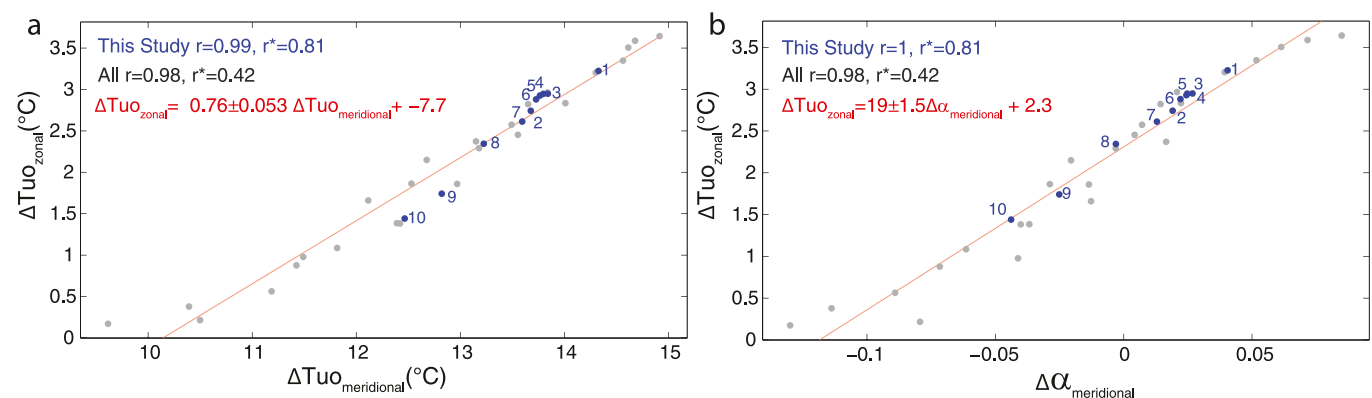

FIG. 13. (a) The equatorial Pacific zonal ( $\left.\Delta T_{\text {uo,zonal }}\right)$ vs Pacific meridional ( $\left.\Delta T_{\text {uo,meridional }}\right)$ upper-ocean gradient, and (b) $\Delta T_{\text {uo,zonal }}$ vs the Pacific meridional TOA albedo gradient $\left(\Delta \alpha_{\text {meridional }}\right)$. See Table 4 for the definition of $\Delta T_{\text {uo,zonal }}, \Delta \mathrm{T}_{\text {uo,meridional }}$, and $\Delta \alpha_{\text {meridional }}$. The light gray dots show results from the abrupt $\mathrm{CO}_{2}$ and modified cloud albedo experiments of Burls and Fedorov (2014a) and Fedorov et al. (2015) for comparison. See Fig. 7 caption for the definitions of $r$ and $r *$ 
LCC is greatest in the mid- and high-latitude oceans, and subtropical eastern Pacific and Atlantic. This response is either enhanced or suppressed by varying the strength of the $\mathrm{LCC}$ response to a $\mathrm{CO}_{2}$ doubling. When the lowcloud feedback is enhanced SST increases more in these regions as well as Pacific cold tongue. Strengthening the LCC feedbacks not only enhances the ECS, but also reduces the zonal and meridional gradients (structural climate sensitivity), resulting in substantial Walker and Hadley strength changes.

This enhancement in the response of meridional and zonal surface temperature gradients to a $\mathrm{CO}_{2}$ doubling could aid in simulating past warm climates like the early Pliocene. On the other hand, SSTs appear to warm too much in the warm pool region relative to available proxy reconstructions. While enhancing the LCC feedback helps by increasing extratropical and cold tongue warming, a negative tropical feedback response is needed to regulate warm pool and GST changes. Burls and Fedorov (2017) show that when a SST warming pattern similar to early Pliocene SST reconstructions is used to force an atmospheric general circulation model, dynamically driven decreases in the meridional moisture transport are able to compensate for the thermodynamically driven increase, thereby supporting wetter subtropics. This does not occur in any of our simulations as the thermodynamic changes, due to large global mean surface temperature changes, always outweigh the dynamical changes due to meridional gradient reduction.

As the LCC feedback is enhanced, the meridional gradient in TOA albedo between the tropical and extratropical Pacific decreases. In the FCM experiments this albedo gradient change is associated with decreasing meridional and zonal upper-ocean temperature gradients in agreement with the coupled box model scaling and the results of Burls and Fedorov (2014a) and Fedorov et al. (2015). Following the idealized box model, the reduction of LCC in the midlatitudes (associated with a weakening of the meridional TOA albedo gradient) increases the amount of solar radiation reaching at ocean surface, leading to a warming of the midlatitude surface ocean and a decrease in the meridional surface temperature gradient. This warming is communicated to the equatorial eastern Pacific by subducting and transporting the midlatitude warm waters via the STCs, leading to a decrease in the equatorial Pacific zonal temperature gradient.

The SST zonal gradient decreases monotonically with the LCC feedback and global SST increases. Our SOM results are similar to the idealized SOM simulations of MS11, and experience the evaporative damping mechanism. In the MS11 idealized cloud-free SOM experiments the zonal latent heat flux gradient is invariant (because of the surface energy balance between the prescribed $Q$ flux and latent heat flux gradients, and the $Q$ flux is unchanged across experiments), and therefore the zonal surface temperature gradient reduces with warming to the extent that saturation specific humidity increases with temperature. Compared to MS11, our SOM results simulate enhanced weakening of the zonal SST gradient for a given global/tropical SST increase due to the presence of clouds, and enhanced cloud feedback strengths. For the FCM experiments, ocean coupling, as encapsulated by the box model, results in further enhancement and substantially weaker zonal gradients with warming. The dynamical ocean-atmosphere coupling in the FCM experiments also allows for a different cloud response along the equator relative to the SOM experiments, unlike in the SOM experiments LCC increases and hence net SW decreases in the eastern Pacific.

When studying the weakening of zonal and meridional gradients across experiments, the relative importance of (i) global warming acting on a fixed warming pattern versus (ii) cloud feedbacks changing the pattern of warming might not seem explicit. For the zonal gradient, Fig. $7 \mathrm{~b}$ addresses the relative importance of (i) and (ii): the MS11 scaling represents a reduction of zonal gradient with surface warming one would expect in the absence of cloud feedbacks and ocean heat transport changes. As seen in our experiments, the cloud feedback further intensifies the weakening of this gradient with global warming, as does the coupling with ocean dynamics. To further investigate the importance of (ii), we isolated the cloud feedback-induced changes from the warming by plotting the change in meridional and zonal gradients, relative to the control, per degree of global mean surface warming across all the $2 \times \mathrm{CO}_{2}$ experiments (figure not shown). The normalized zonal and meridional gradients do change across experiments in response to the modified cloud feedback strengths, indicating that cloud feedback strength changes the pattern of warming.

While we have not explicitly quantified them, the other climate feedback mechanisms are of course operating together with the perturbed LLC feedback to determine the structure of surface warming and hence the meridional and zonal temperature gradient response to warming. As reviewed by Roe et al. (2015), multiple feedback mechanisms contribute to the meridional structure of warming, but by design the central feedback changing across our experiments is the LCC feedback and as such it is the central mechanism operating to modify the gradient response between our respective $\mathrm{CO}_{2}$ doubling experiments.

Our findings provide a framework upon which to interpret the influence of LCC feedback strength on the 
structure of surface temperature and circulation change under $\mathrm{CO}_{2}$-induced warming. One caveat in our approach is that the spatial structure of our LCC feedback largely scales with the inherent structure of the LCC feedback seen within the control simulation (in which no modification is made to the $c$ parameter) in response to a $\mathrm{CO}_{2}$ doubling (Exp 2 and 12). One might ask how sensitive are our results to variations in the pattern of the LCC feedback from one model to another? We plan to investigate this in the future research, but for now we speculate that if a model simulates an enhanced reduction in LCC in the midlatitudes in response to a $\mathrm{CO}_{2}$ doubling and the consequent global warming, it will generally reproduce our results. Zelinka et al. (2012) analyzed $2 \times \mathrm{CO}_{2}$ experiments from $11 \mathrm{GCMs}$ in the first phase of the Cloud Feedback Model Intercomparison Project (CFMIP1) and calculated the annual ensemble mean change in total cloud fraction normalized by the increase in global surface air temperature (see their Fig. 1a). More than $75 \%$ of the CFMIP1 models show a decrease in cloud fraction in the midlatitudes $\left(30^{\circ}-60^{\circ} \mathrm{N} / \mathrm{S}\right)$ as a result of warming by doubling $\mathrm{CO}_{2}$. Although not a direct comparison, our Fig. 3a agrees reasonably well with Fig. 1a in Zelinka et al. (2012). Therefore, we speculate that most GCMs (in particular, the models that show an enhanced positive low-level cloud amount feedback in the midlatitudes) would produce results similar to our findings.

Acknowledgments. This study was supported by the National Science Foundation (NSF; AGS-1613318, AGS-1338427), the National Aeronautics and Space Administration (NASA; NNX14AM19G), and the National Oceanic and Atmospheric Administration (NOAA; NA14OAR4310160). N.J.B. is supported by the Alfred P. Sloan Foundation as a Research Fellow. We thank two anonymous reviewers for their constructive comments that greatly improved this paper. We would like to acknowledge high-performance computing support from Cheyenne (https://doi.org/10.5065/D6RX99HX) provided by NCAR's Computational and Information Systems Laboratory, sponsored by the NSF. We thank Zaiyu Wang for his guidance in setting up the CESM SOM simulations.

\section{REFERENCES}

Abbot, D. S., and E. Tziperman, 2008a: Sea ice, high-latitude convection, and equable climates. Geophys. Res. Lett., 35, L03702, https://doi.org/10.1029/2007GL032286.

, and - 2008b: A high-latitude convective cloud feedback and equable climates. Quart. J. Roy. Meteor. Soc., 134, 165185, https://doi.org/10.1002/qj.211.
Andrews, T., and M. J. Webb, 2018: The dependence of global cloud and lapse rate feedbacks on the spatial structure of tropical Pacific warming. J. Climate, 31, 641-654, https:// doi.org/10.1175/JCLI-D-17-0087.1.

- J. M. Gregory, and M. J. Webb, 2015: The dependence of radiative forcing and feedback on evolving patterns of surface temperature change in climate models. J. Climate, 28, 1630-1648, https://doi.org/10.1175/JCLI-D-14-00545.1.

Armour, K. C., C. M. Bitz, and G. H. Roe, 2013: Time-varying climate sensitivity from regional feedbacks. J. Climate, 26, 4518-4534, https://doi.org/10.1175/JCLI-D-12-00544.1.

Bony, S., and J. L. Dufresne, 2005: Marine boundary layer clouds at the heart of tropical cloud feedback uncertainties in climate models. Geophys. Res. Lett., 32, L20806, https://doi.org/10.1029/ 2005GL023851.

— uate climate change feedback processes? J. Climate, 19, 3445-3482, https://doi.org/10.1175/JCLI3819.1.

Boucher, O., and Coauthors, 2013: Clouds and aerosols. Climate Change 2013: The Physical Science Basis, T. F. Stocker et al., Eds., Cambridge University Press, 571-657.

Bretherton, C. S., 2015: Insights into low-latitude cloud feedbacks from high-resolution models. Philos. Trans. Roy. Soc., 373A, 20140415, https://doi.org/10.1098/rsta.2014.0415.

Brient, F., T. Schneider, Z. H. Tan, S. Bony, X. Qu, and A. Hall, 2016: Shallowness of tropical low clouds as a predictor of climate models' response to warming. Climate Dyn., 47, 433-449, https://doi.org/10.1007/s00382-015-2846-0.

Broccoli, A. J., K. A. Dahl, and R. J. Stouffer, 2006: Response of the ITCZ to Northern Hemisphere cooling. Geophys. Res. Lett., 33, L01702, https://doi.org/10.1029/2005GL024546.

Burls, N. J., and A. V. Fedorov, 2014a: What controls the mean east-west sea surface temperature gradient in the equatorial Pacific: The role of cloud albedo. J. Climate, 27, 2757-2778, https://doi.org/10.1175/JCLI-D-13-00255.1.

— nent El Niño-like state: The role of cloud albedo. Paleoceanography, 29, 893-910, https://doi.org/10.1002/2014PA002644.

— and — 2017: Wetter subtropics in a warmer world: Contrasting past and future hydrological cycles. Proc. Natl. Acad. Sci. USA, 114, 12 888-12 893, https://doi.org/10.1073/pnas.1703421114.

_ L. Muir, E. M. Vincent, and A. Fedorov, 2017: Extra-tropical origin of equatorial Pacific cold bias in climate models with links to cloud albedo. Climate Dyn., 49, 2093-2113, https:// doi.org/10.1007/s00382-016-3435-6.

Caldwell, P. M., M. D. Zelinka, K. E. Taylor, and K. Marvel, 2016: Quantifying the sources of intermodel spread in equilibrium climate sensitivity. J. Climate, 29, 513-524, https://doi.org/ 10.1175/JCLI-D-15-0352.1.

Ceppi, P., and J. M. Gregory, 2017: Relationship of tropospheric stability to climate sensitivity and Earth's observed radiation budget. Proc. Natl. Acad. Sci. USA, 114, 13 126-13131, https:// doi.org/10.1073/pnas.1714308114.

— M. D. Zelinka, and D. L. Hartmann, 2014: The response of the Southern Hemispheric eddy-driven jet to future changes in shortwave radiation in CMIP5. Geophys. Res. Lett., 41, 32443250, https://doi.org/10.1002/2014GL060043.

Clement, A. C., R. Seager, M. A. Cane, and S. E. Zebiak, 1996: An ocean dynamical thermostat. J. Climate, 9, 2190-2196, https:// doi.org/10.1175/1520-0442(1996)009<2190:AODT>2.0.CO;2.

Collins, M., and Coauthors, 2010: The impact of global warming on the tropical Pacific Ocean and El Niño. Nat. Geosci., 3, 391397, https://doi.org/10.1038/ngeo868. 
Collins, W. D., and Coauthors, 2004: Description of the NCAR Community Atmosphere Model (CAM 3.0). NCAR Tech. Note NCAR/TN-464+STR, 226 pp., https://doi.org/10.5065/ D63N21CH.

Cronin, T. W., and E. Tziperman, 2015: Low clouds suppress Arctic air formation and amplify high-latitude continental winter warming. Proc. Natl. Acad. Sci. USA, 112, 11490-11495, https://doi.org/10.1073/pnas.1510937112.

-, H. Li, and E. Tziperman, 2017: Suppression of Arctic air formation with climate warming: Investigation with a twodimensional cloud-resolving model. J. Atmos. Sci., 74, 2717 2736, https://doi.org/10.1175/JAS-D-16-0193.1.

Dowsett, H. J., and Coauthors, 2013: Sea surface temperature of the mid-Piacenzian Ocean: A data-model comparison. Sci. Rep., 3, 2013, https://doi.org/10.1038/srep02013.

Eastman, R., and S. G. Warren, 2013: A 39-yr survey of cloud changes from land stations worldwide 1971-2009: Longterm trends, relation to aerosols, and expansion of the tropical belt. J. Climate, 26, 1286-1303, https://doi.org/ 10.1175/JCLI-D-12-00280.1.

Evans, D., and Coauthors, 2018: Eocene greenhouse climate revealed by coupled clumped isotope- $\mathrm{Mg} / \mathrm{Ca}$ thermometry Proc. Natl. Acad. Sci. USA, 115, 1174-1179, https://doi.org/ 10.1073/pnas.1714744115.

Fedorov, A. V., C. M. Brierley, K. T. Lawrence, Z. Liu, P. S. Dekens, and A. C. Ravelo, 2013: Patterns and mechanisms of early Pliocene warmth. Nature, 496, 43-49, https://doi.org/10.1038/nature12003.

—, N. J. Burls, K. T. Lawrence, and L. C. Peterson, 2015: Tightly linked zonal and meridional sea surface temperature gradients over the past five million years. Nat. Geosci., 8, 975-980, https://doi.org/10.1038/ngeo2577.

Flato, G., and Coauthors, 2013: Evaluation of climate models. Climate Change 2013: The Physical Science Basis, T. F. Stocker et al., Eds., Cambridge University Press, 741-866, https:// doi.org/10.1017/CBO9781107415324.020.

Geoffroy, O., S. C. Sherwood, and D. Fuchs, 2017: On the role of the stratiform cloud scheme in the inter-model spread of cloud feedback. J. Adv. Model. Earth Syst., 9, 423-437, https:// doi.org/10.1002/2016MS000846.

Goldner, A., N. Herold, and M. Huber, 2014: The challenge of simulating the warmth of the mid-Miocene climatic optimum in CESM1. Climate Past, 10, 523-536, https://doi.org/10.5194/ cp-10-523-2014.

Grise, K. M., and L. M. Polvani, 2014: Is climate sensitivity related to dynamical sensitivity? A Southern Hemisphere perspective. Geophys. Res. Lett., 41, 534-540, https://doi.org/10.1002/ 2013GL058466.

Held, I. M., and B. J. Soden, 2006: Robust responses of the hydrological cycle to global warming. J. Climate, 19, 5686-5699, https://doi.org/10.1175/JCLI3990.1.

Huber, M., 2013: A sensitivity to history. Nat. Geosci., 6, 15-16, https://doi.org/10.1038/ngeo1695.

- , and R. Caballero, 2011: The early Eocene equable climate problem revisited. Climate Past, 7, 603-633, https://doi.org/ 10.5194/cp-7-603-2011.

IPCC, 2013: Climate Change 2013: The Physical Science Basis. T. F. Stocker et al., Eds., Cambridge University Press, 1535 pp.

Kang, S. M., I. M. Held, D. M. W. Frierson, and M. Zhao, 2008: The response of the ITCZ to extratropical thermal forcing: Idealized slab-ocean experiments with a GCM. J. Climate, 21, 3521-3532, https://doi.org/10.1175/2007JCLI2146.1.

Kiehl, J. T., and C. A. Shields, 2013: Sensitivity of the PalaeoceneEocene Thermal Maximum climate to cloud properties. Philos.
Trans. Roy. Soc., 371A, 20130093, https://doi.org/10.1098/ rsta.2013.0093.

Kirk-Davidoff, D. B., D. P. Schrag, and J. G. Anderson, 2002: On the feedback of stratospheric clouds on polar climate. Geophys. Res. Lett., 29, 1556, https://doi.org/10.1029/2002GL014659.

Klein, S. A., and D. L. Hartmann, 1993: The seasonal cycle of low stratiform clouds. J. Climate, 6, 1587-1606, https://doi.org/ 10.1175/1520-0442(1993)006<1587:TSCOLS $>2.0$. CO 2 .

Knutson, T. R., and S. Manabe, 1995: Time-mean response over the tropical Pacific to increased $\mathrm{CO}_{2}$ in a coupled oceanatmosphere model. J. Climate, 8, 2181-2199, https://doi.org/ 10.1175/1520-0442(1995)008<2181:TMROTT >2.0.CO;2.

Kump, L. R., and D. Pollard, 2008: Amplification of cretaceous warmth by biological cloud feedbacks. Science, 320, 195, https://doi.org/10.1126/science.1153883.

Lin, B., and Coauthors, 2010: Estimations of climate sensitivity based on top-of-atmosphere radiation imbalance. Atmos. Chem. Phys., 10, 1923-1930, https://doi.org/10.5194/acp-10-1923-2010.

Lipat, B. R., G. Tselioudis, K. M. Grise, and L. M. Polvani, 2017: CMIP5 models' shortwave cloud radiative response and climate sensitivity linked to the climatological Hadley cell extent. Geophys. Res. Lett., 44, 5739-5748, https://doi.org/ 10.1002/2017GL073151.

Liu, Z. Y., 1998: The role of ocean in the response of tropical climatology to global warming: The west-east SST contrast. J. Climate, 11, 864-875, https://doi.org/10.1175/1520-0442(1998)011<0864: TROOIT > 2.0.CO;2. , and B. Y. Huang, 1997: A coupled theory of tropical climatology: Warm pool, cold tongue, and Walker circulation. J. Climate, 10, 1662-1679, https://doi.org/10.1175/15200442(1997)010<1662:ACTOTC $>2.0$. CO 2 .

Lunt, D. J., and Coauthors, 2013: Warm climates of the past-A lesson for the future? Philos. Trans. Roy. Soc., 371A, 20130146, https://doi.org/10.1098/rsta.2013.0146.

Luo, Y. Y., J. Lu, F. K. Liu, and O. Garuba, 2017: The role of ocean dynamical thermostat in delaying the El Niño-like response over the equatorial Pacific to climate warming. J. Climate, $\mathbf{3 0}$, 2811-2827, https://doi.org/10.1175/JCLI-D-16-0454.1.

Marshall, J., J. R. Scott, K. C. Armour, J. M. Campin, M. Kelley, and A. Romanou, 2015: The ocean's role in the transient response of climate to abrupt greenhouse gas forcing. Climate Dyn., $\mathbf{4 4}$, 2287-2299, https://doi.org/10.1007/s00382-014-2308-0.

Mauritsen, T., 2016: Clouds cooled the Earth. Nat. Geosci., 9, 865867, https://doi.org/10.1038/ngeo2838.

and B. Stevens, 2015: Missing iris effect as a possible cause of muted hydrological change and high climate sensitivity in models. Nat. Geosci., 8, 346-351, https://doi.org/10.1038/ngeo2414.

Merlis, T. M., and T. Schneider, 2011: Changes in zonal surface temperature gradients and Walker circulations in a wide range of climates. J. Climate, 24, 4757-4768, https://doi.org/10.1175/ 2011JCLI4042.1.

Norris, J. R., R. J. Allen, A. T. Evan, M. D. Zelinka, C. W. O'Dell, and S. A. Klein, 2016: Evidence for climate change in the satellite cloud record. Nature, 536, 72-75, https://doi.org/10.1038/ nature 18273

Otto, A., and Coauthors, 2013: Energy budget constraints on climate response. Nat. Geosci., 6, 415-416, https://doi.org/10.1038/ ngeo1836.

Peters, R. B., and L. C. Sloan, 2000: High concentrations of greenhouse gases and polar stratospheric clouds: A possible solution to high-latitude faunal migration at the latest Paleocene thermal maximum. Geology, 28, 979-982, https://doi.org/ 10.1130/0091-7613(2000)28<979:HCOGGA > 2.0.CO;2. 
Rayner, N. A., D. E. Parker, E. B. Horton, C. K. Folland, L. V. Alexander, D. P. Rowell, E. C. Kent, and A. Kaplan, 2003: Global analyses of sea surface temperature, sea ice, and night marine air temperature since the late nineteenth century. J. Geophys. Res., 108, 4407, https://doi.org/10.1029/2002JD002670.

Roe, G. H., N. Feldl, K. C. Armour, Y. T. Hwang, and D. M. W. Frierson, 2015: The remote impacts of climate feedbacks on regional climate predictability. Nat. Geosci., 8, 135-139, https://doi.org/10.1038/ngeo2346.

Sagoo, N., P. Valdes, R. Flecker, and L. J. Gregoire, 2013: The early Eocene equable climate problem: Can perturbations of climate model parameters identify possible solutions? Philos. Trans. Roy. Soc., 371A, 20130123, https://doi.org/10.1098/ rsta.2013.0123.

Salzmann, U., and Coauthors, 2013: Challenges in quantifying Pliocene terrestrial warming revealed by data-model discord. Nat. Climate Change, 3, 969-974, https://doi.org/10.1038/nclimate2008.

Seager, R., and R. Murtugudde, 1997: Ocean dynamics, thermocline adjustment, and regulation of tropical SST. J. Climate, 10, 521-534, https://doi.org/10.1175/1520-0442(1997)010<0521: ODTAAR $>2.0 . \mathrm{CO} ; 2$.

Shaw, T. A., and Coauthors, 2016: Storm track processes and the opposing influences of climate change. Nat. Geosci., 9, 656664, https://doi.org/10.1038/ngeo2783.

Sherwood, S. C., S. Bony, and J. L. Dufresne, 2014: Spread in model climate sensitivity traced to atmospheric convective mixing. Nature, 505, 37-42, https://doi.org/10.1038/nature12829.

Shields, C. A., D. A. Bailey, G. Danabasoglu, M. Jochum, J. T. Kiehl, S. Levis, and S. Park, 2012: The low-resolution CCSM4. J. Climate, 25, 3993-4014, https://doi.org/10.1175/JCLI-D-11-00260.1.

Sloan, L. C., and E. J. Barron, 1990: "Equable" climates during Earth history? Geology, 18, 489-492, https://doi.org/10.1130/ 0091-7613(1990)018<0489:ECDEH >2.3.CO;2.

— J. C. G. Walker, T. C. Moore, D. K. Rea, and J. C. Zachos, 1992: Possible methane-induced polar warming in the early Eocene. Nature, 357, 320-322, https://doi.org/10.1038/357320a0.

Sun, D. Z., and Z. Y. Liu, 1996: Dynamic ocean-atmosphere coupling: A thermostat for the tropics. Science, 272, 11481150, https://doi.org/10.1126/science.272.5265.1148.

Tomassini, L., A. Voigt, and B. Stevens, 2015: On the connection between tropical circulation, convective mixing, and climate sensitivity. Quart. J. Roy. Meteor. Soc., 141, 1404-1416, https:// doi.org/10.1002/qj.2450.
Tselioudis, G., B. R. Lipat, D. Konsta, K. M. Grise, and L. M. Polvani, 2016: Midlatitude cloud shifts, their primary link to the Hadley cell, and their diverse radiative effects. Geophys. Res. Lett., 43, 4594-4601, https://doi.org/10.1002/ 2016 GL068242.

Unger, N., and X. Yue, 2014: Strong chemistry-climate feedbacks in the Pliocene. Geophys. Res. Lett., 41, 527-533, https:// doi.org/10.1002/2013GL058773.

Upchurch, G. R., J. Kiehl, C. Shields, J. Scherer, and C. Scotese, 2015: Latitudinal temperature gradients and high-latitude temperatures during the latest Cretaceous: Congruence of geologic data and climate models. Geology, 43, 683-686, https://doi.org/10.1130/G36802.1.

Vial, J., J. L. Dufresne, and S. Bony, 2013: On the interpretation of inter-model spread in CMIP5 climate sensitivity estimates. Climate Dyn., 41, 3339-3362, https://doi.org/10.1007/ s00382-013-1725-9.

_ - S. Bony, B. Stevens, and R. Vogel, 2017: Mechanisms and model diversity of trade-wind shallow cumulus cloud feedbacks: A review. Surv. Geophys., 38, 1331-1353, https:// doi.org/10.1007/s10712-017-9418-2.

Wang, C., L. Zhang, S. Lee, L. Wu, and C. R. Mechoso, 2014: A global perspective on CMIP5 climate model biases. Nat. Climate Change, 4, 201-205, https://doi.org/10.1038/nclimate2118.

Webb, M. J., and Coauthors, 2006: On the contribution of local feedback mechanisms to the range of climate sensitivity in two GCM ensembles. Climate Dyn., 27, 17-38, https://doi.org/ 10.1007/s00382-006-0111-2.

Xie, S. P., C. Deser, G. A. Vecchi, J. Ma, H. Y. Teng, and A. T. Wittenberg, 2010: Global warming pattern formation: Sea surface temperature and rainfall. J. Climate, 23, 966-986, https://doi.org/10.1175/2009JCLI3329.1.

Zelinka, M. D., S. A. Klein, and D. L. Hartmann, 2012: Computing and partitioning cloud feedbacks using cloud property histograms. Part II: Attribution to changes in cloud amount, altitude, and optical depth. J. Climate, 25, 3736-3754, https:// doi.org/10.1175/JCLI-D-11-00249.1.

_ D. A. Randall, M. J. Webb, and S. A. Klein, 2017: Clearing clouds of uncertainty. Nat. Climate Change, 7, 674-678, https:// doi.org/10.1038/nclimate3402.

Zhou, C., M. D. Zelinka, and S. A. Klein, 2016: Impact of decadal cloud variations on the Earth's energy budget. Nat. Geosci., 9, 871-874, https://doi.org/10.1038/ngeo2828. 